\title{
Synthesis of Substituted Phthalimides via Ultrasound-Promoted One-pot Multicomponent Reaction
}

\author{
Abdolali Alizadeh, ${ }^{* a}$ Behnaz Farajpour, ${ }^{\mathrm{a}}$ Christoph Janiak, ${ }^{\mathrm{b}}$ Tim-Oliver Knedel ${ }^{\mathrm{b}}$ \\ ${ }^{a}$ Department of Chemistry, Tarbiat Modares University, P. O. Box 14115-175, Tehran, Iran, \\ aalizadeh@rmodares.ac.ir,Tell: +98-21-82884402,Fax: +98-21-82883455 \\ ${ }^{b}$ Institut für Anorganische Chemie, und Strukturchemie Heinrich-Heine-Universität Düsseldorf, \\ I40225 Düsseldorf
}

Table of Contents:

\begin{tabular}{|c|c|}
\hline IR ${ }^{1} \mathrm{H},{ }^{13} \mathrm{C}$ NMR and Mass spectra of $\mathbf{6 a}$ & S2-S5 \\
\hline $\mathrm{IR},{ }^{1} \mathrm{H},{ }^{13} \mathrm{C}$ NMR and Mass spectra of $\mathbf{6 b}$ & S6-S9 \\
\hline IR ${ }^{1} \mathrm{H},{ }^{13} \mathrm{C}$ NMR and Mass spectra of $\mathbf{6 c}$ & S10-S13 \\
\hline $\mathrm{IR},{ }^{1} \mathrm{H},{ }^{13} \mathrm{C}$ NMR and Mass spectra of $\mathbf{6 d}$ & S14-S17 \\
\hline IR ${ }^{1} \mathrm{H},{ }^{13} \mathrm{C}$ NMR and Mass spectra of $6 \mathrm{e}$ & S18-S21 \\
\hline IR ${ }^{1} \mathrm{H},{ }^{13} \mathrm{C}$ NMR and Mass spectra of $\mathbf{6 f}$ & $\mathrm{S} 22-\mathrm{S} 25$ \\
\hline $\mathrm{IR},{ }^{1} \mathrm{H},{ }^{13} \mathrm{C}$ NMR and Mass spectra of $\mathbf{6 g}$ & S26-S29 \\
\hline $\mathrm{IR},{ }^{1} \mathrm{H},{ }^{13} \mathrm{C}$ NMR and Mass spectra of $\mathbf{6 h}$ & S30-S33 \\
\hline $\mathrm{IR},{ }^{1} \mathrm{H},{ }^{13} \mathrm{C}$ NMR and Mass spectra of $\mathbf{6}^{\prime} \mathbf{a}$ & S34-S37 \\
\hline $\mathrm{IR},{ }^{1} \mathrm{H},{ }^{13} \mathrm{C}$ NMR and Mass spectra of $\mathbf{6}^{\prime} \mathbf{b}$ & S38-S41 \\
\hline $\mathrm{IR},{ }^{1} \mathrm{H},{ }^{13} \mathrm{C}$ NMR and Mass spectra of $\mathbf{6}^{\prime} \mathbf{c}$ & S42-S45 \\
\hline Ortep diagram of compound $\mathbf{6 a}^{\prime}$. The ellipsoid contour of probability level is $50 \%$. & S46 \\
\hline
\end{tabular}




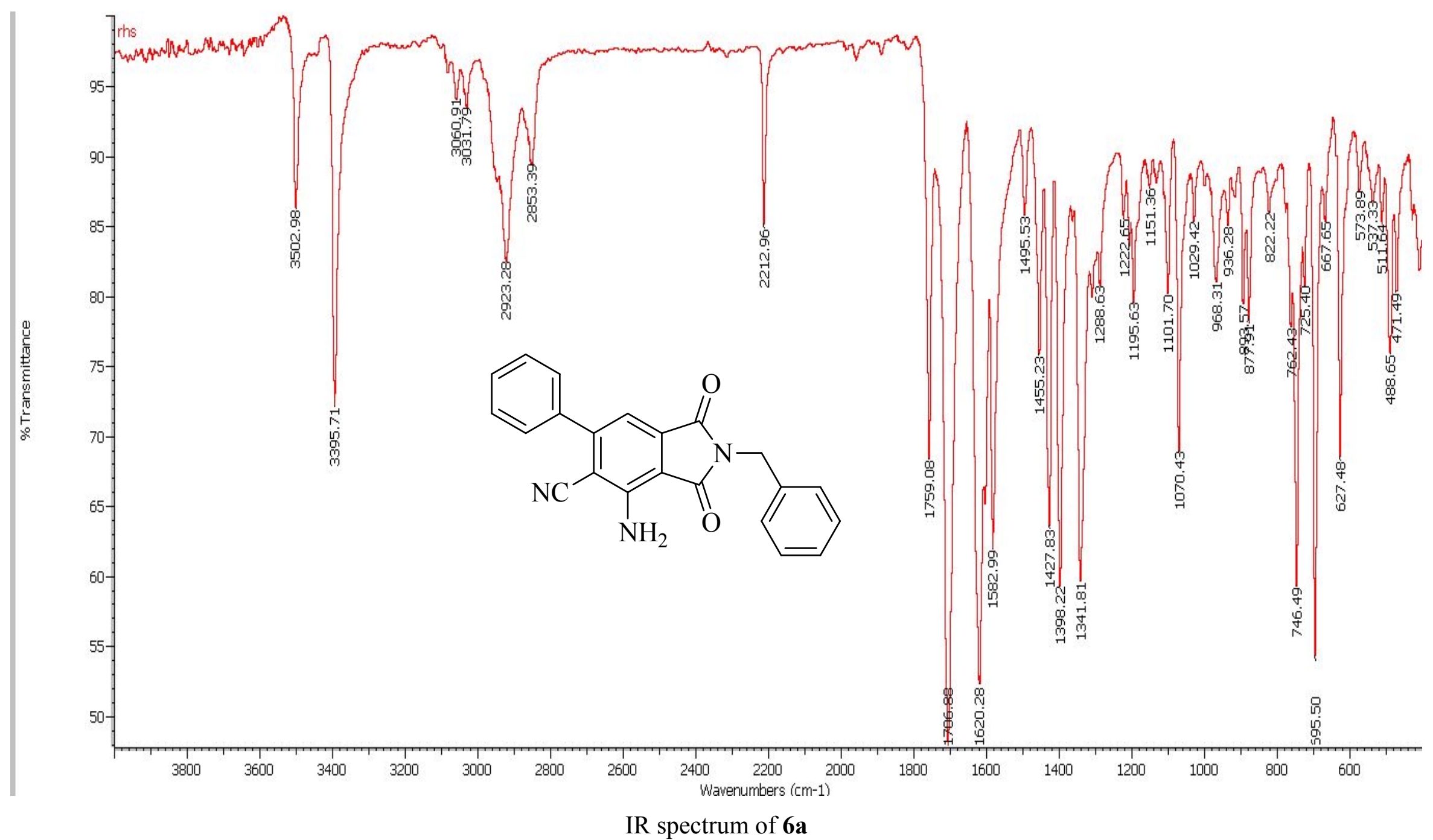




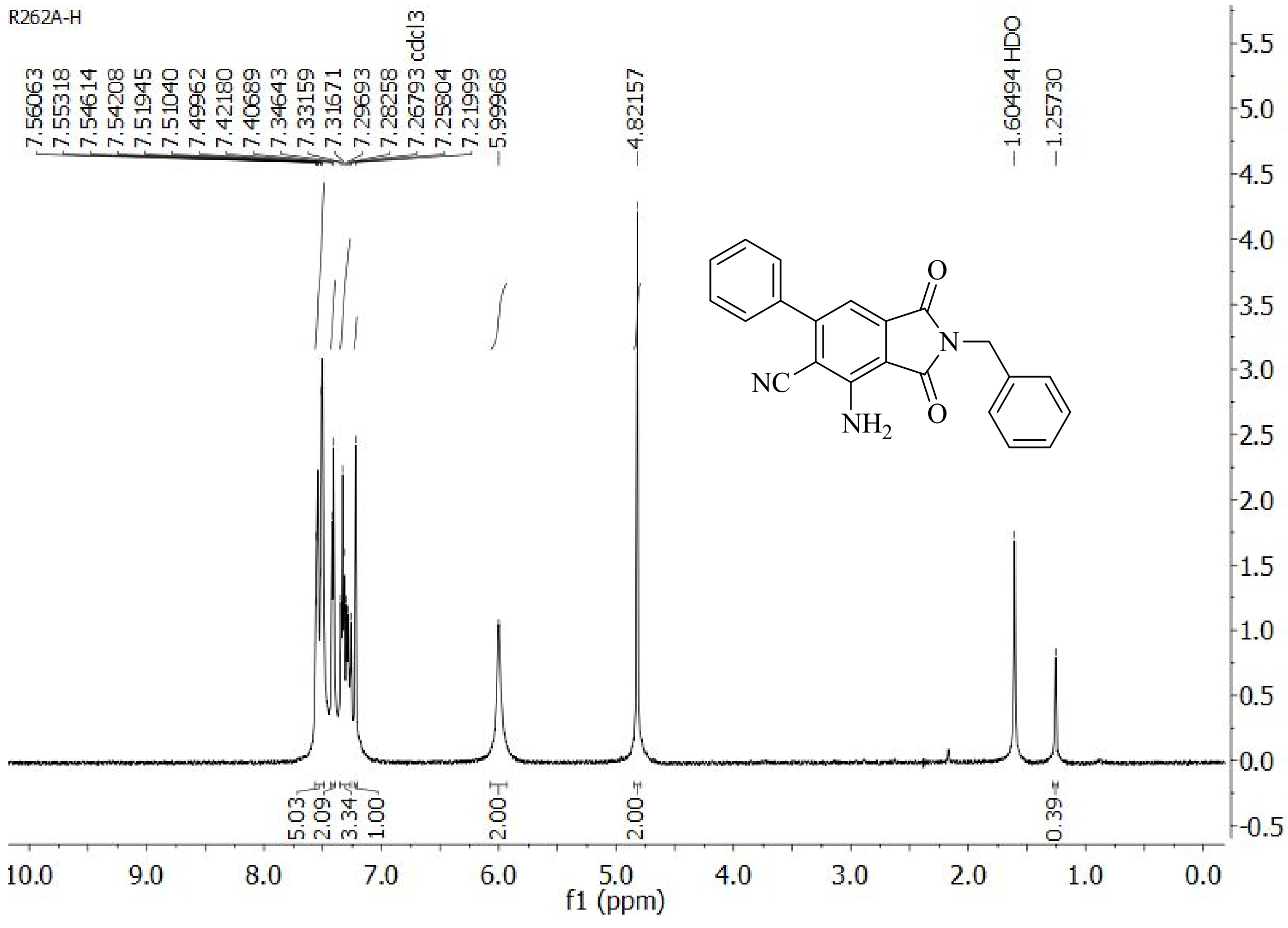

${ }^{1} \mathrm{H} \mathrm{NMR}\left(\mathrm{CDCl}_{3}, 500 \mathrm{MHz}\right)$ spectrum of $\mathbf{6 a}$ 


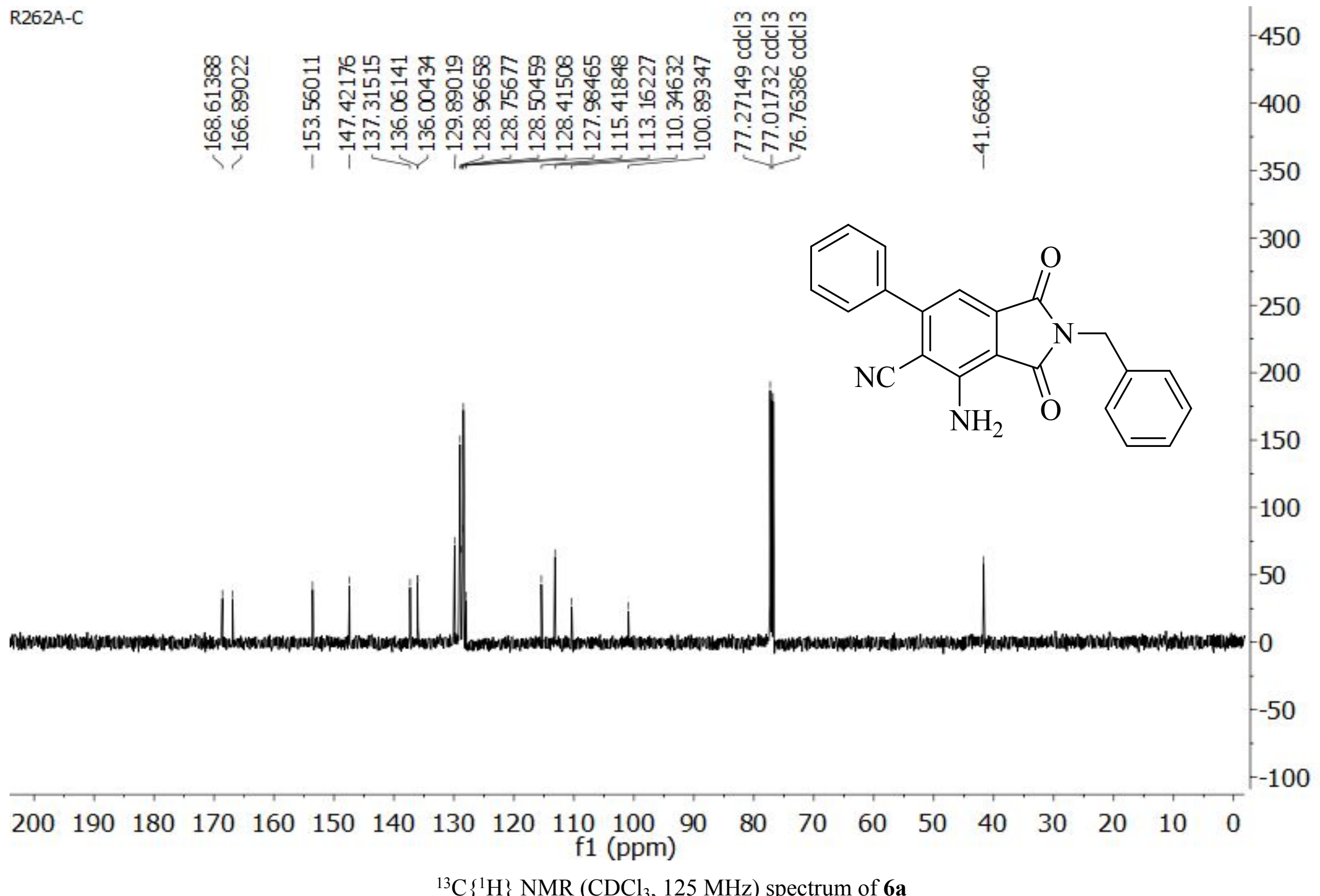

${ }^{13} \mathrm{C}\left\{{ }^{1} \mathrm{H}\right\}$ NMR $\left(\mathrm{CDCl}_{3}, 125 \mathrm{MHz}\right)$ spectrum of $\mathbf{6 a}$ 


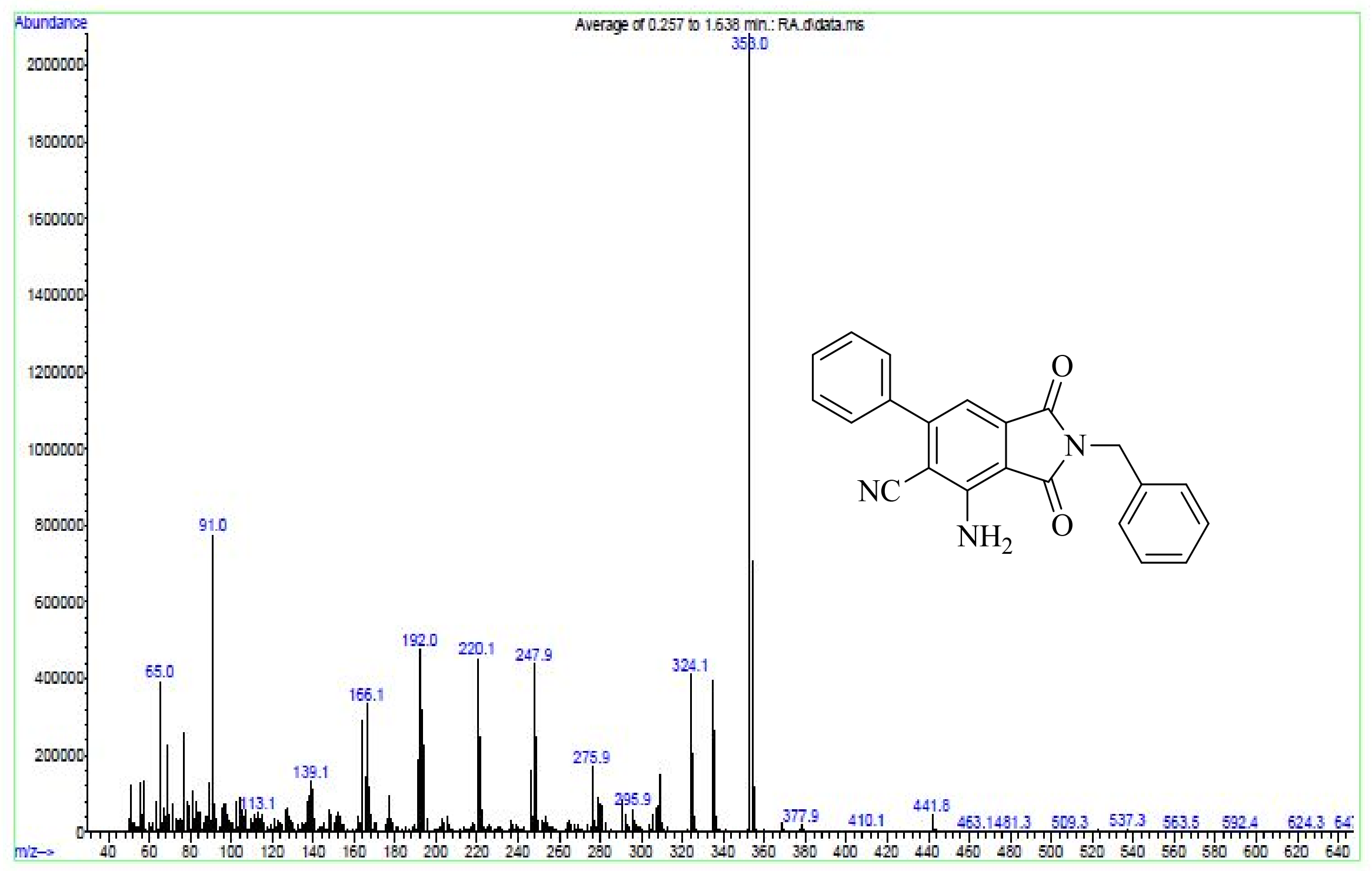

Mass Spectrum of $\mathbf{6 a}$ 


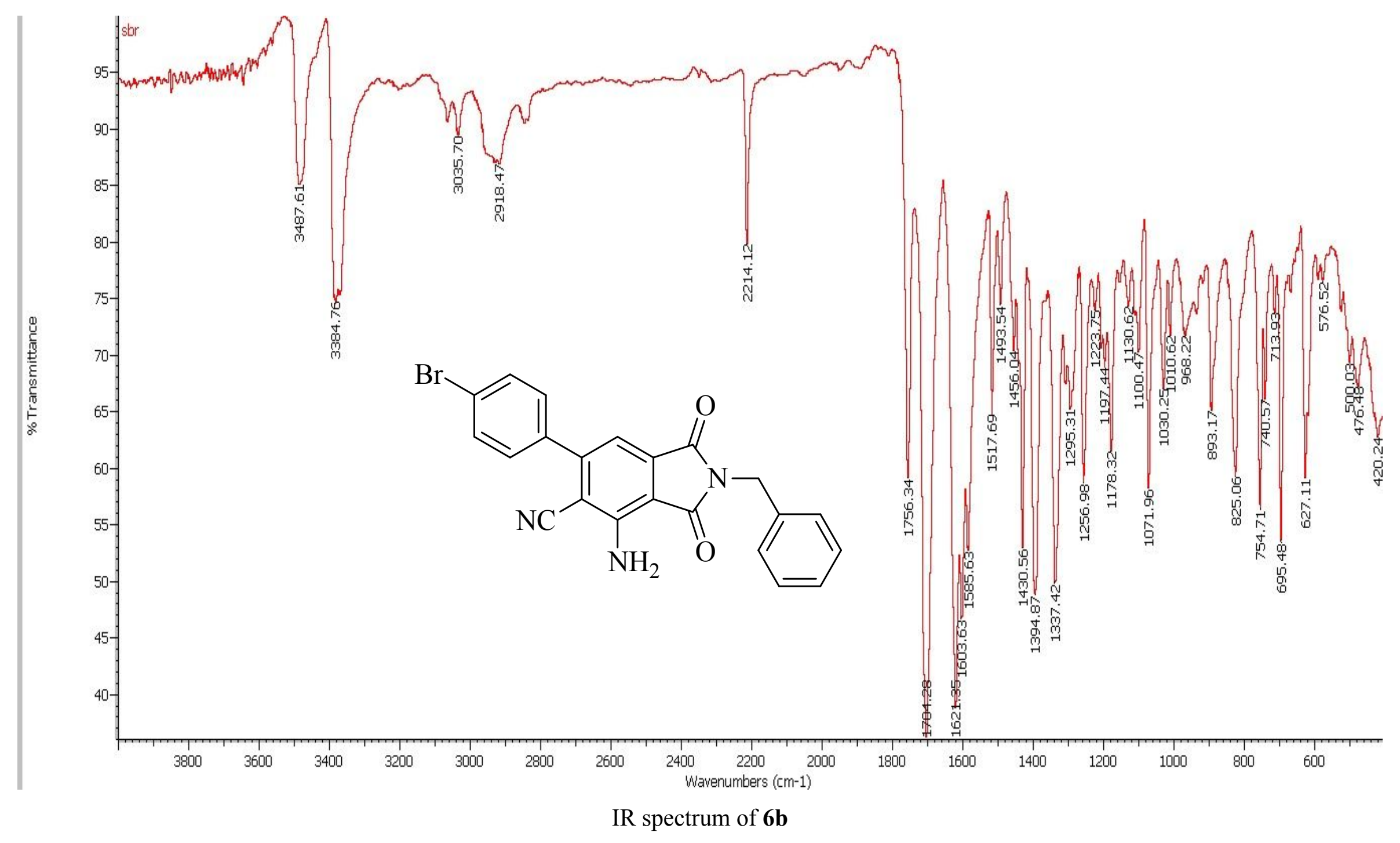




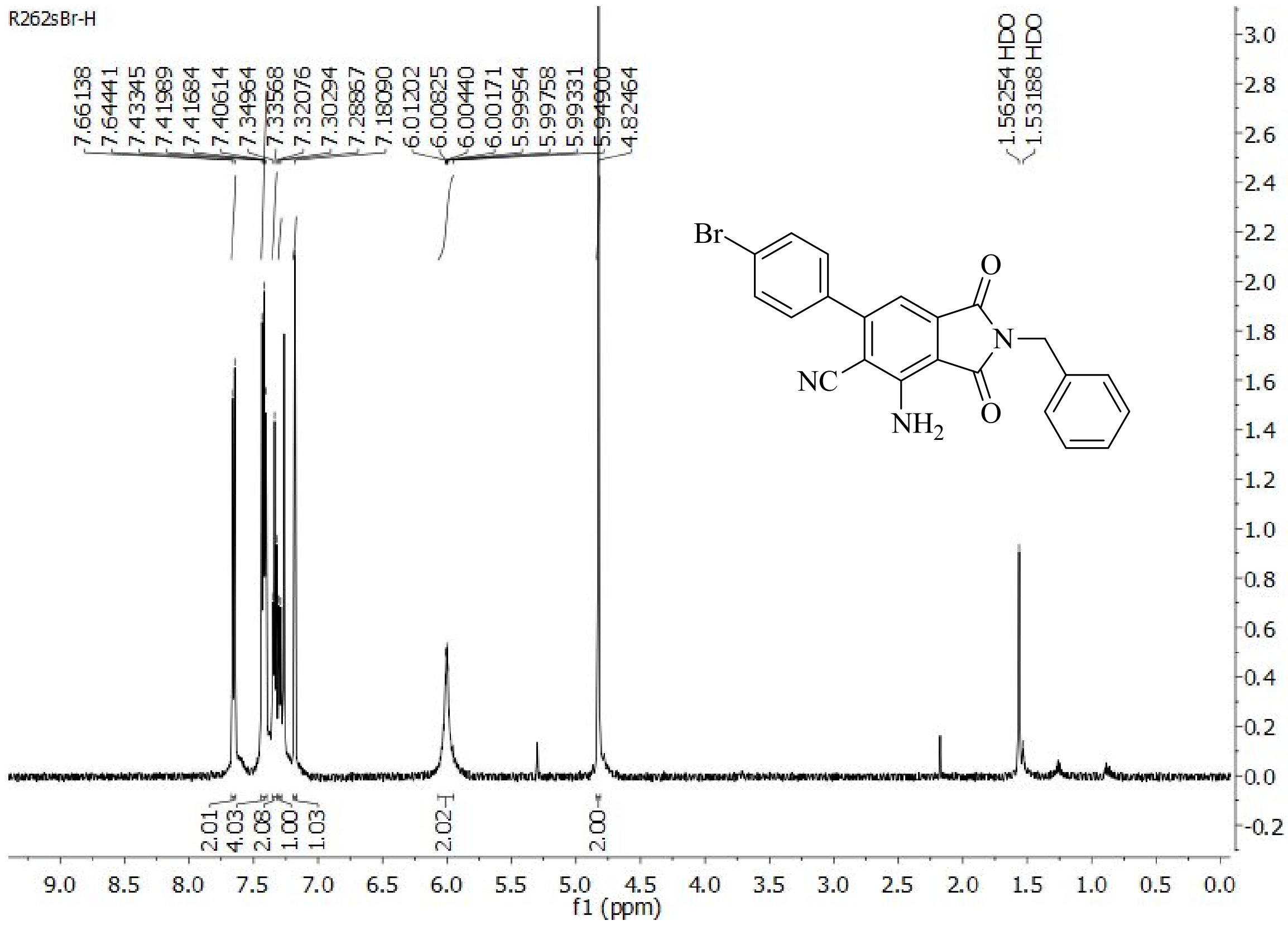

${ }^{1} \mathrm{H}$ NMR $\left(\mathrm{CDCl}_{3}, 500 \mathrm{MHz}\right)$ spectrum of $\mathbf{6 b}$ 
$\mathrm{R} 262 \mathrm{sBr}-\mathrm{C}$

new experiment
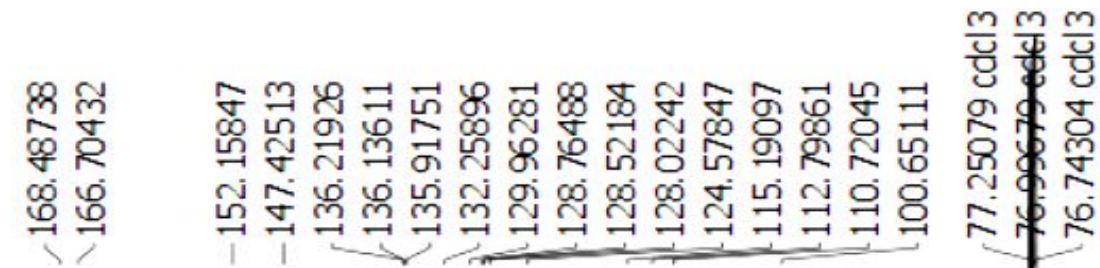<smiles>N#Cc1c(-c2ccc(I)cc2)cc2c(c1N)C(=O)N(Cc1ccccc1)C2=O</smiles>
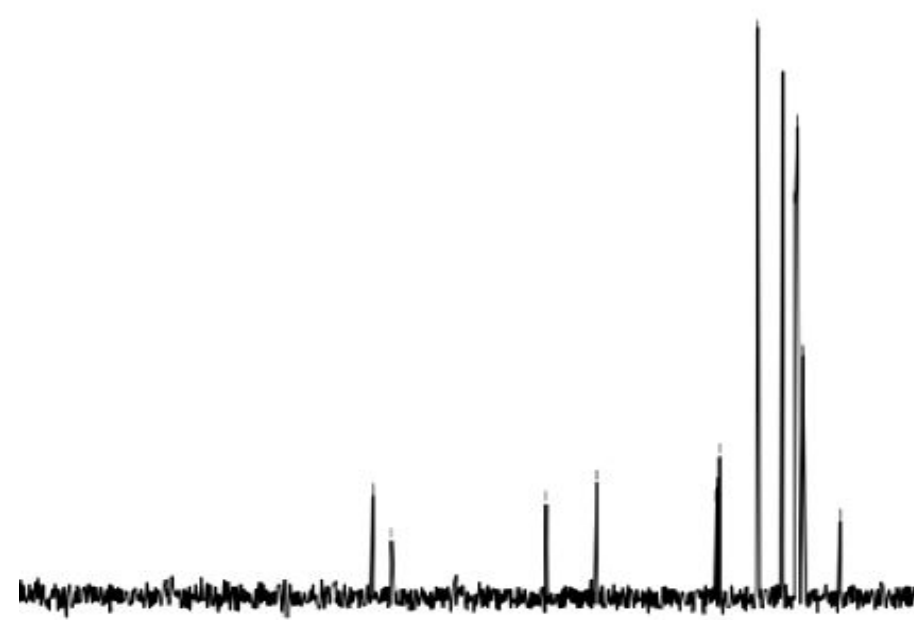

$$
\mathrm{Br}
$$

!00 190

$180 \quad 170$

160

150140

130

120

11010090

80

60

50

$40 \quad 30$

20

100

${ }^{13} \mathrm{C}\left\{{ }^{1} \mathrm{H}\right\} \mathrm{NMR}\left(\mathrm{CDCl}_{3}, 125 \mathrm{MHz}\right)$ spectrum of $6 \mathbf{b}$ 


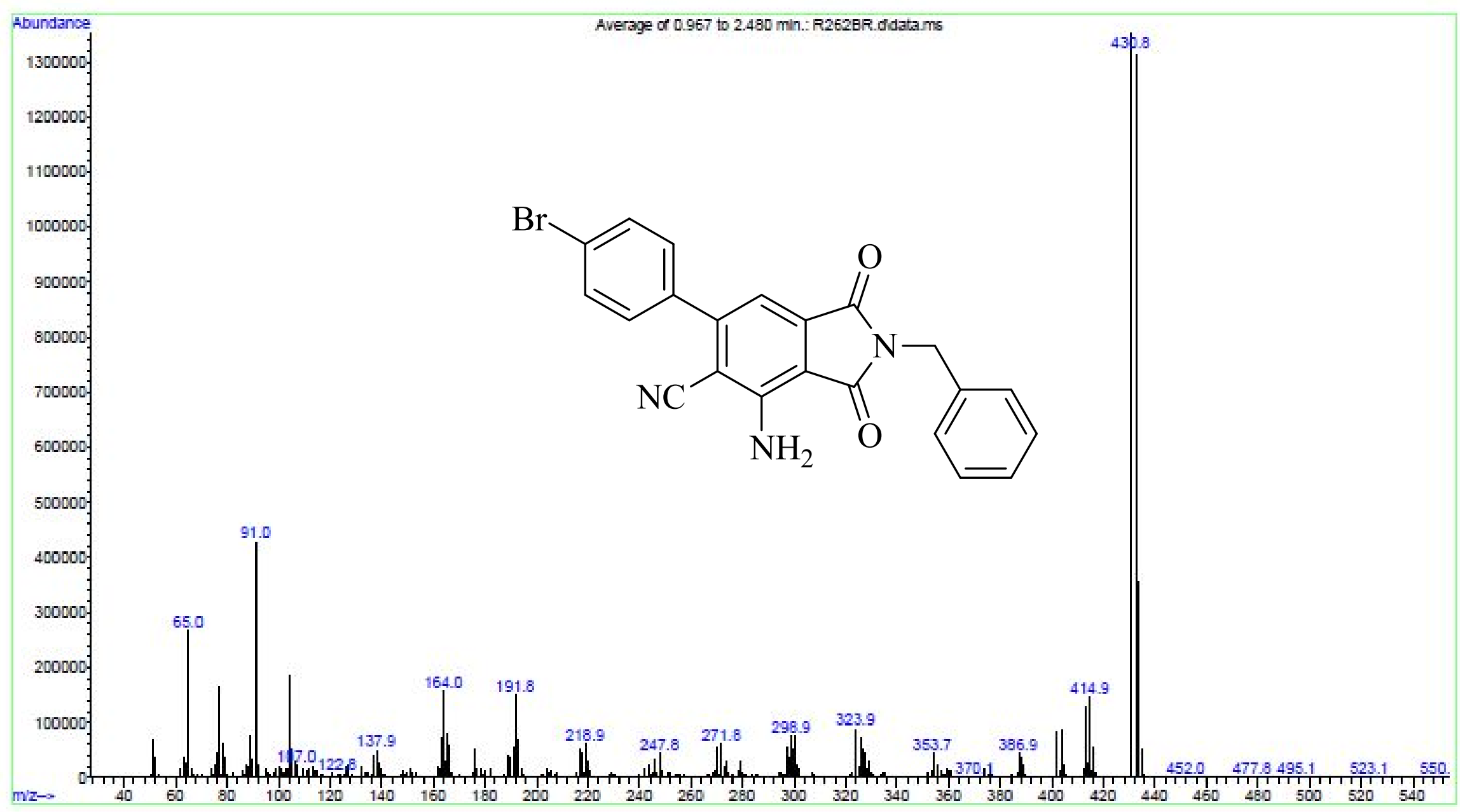

Mass Spectrum of $\mathbf{6 b}$ 


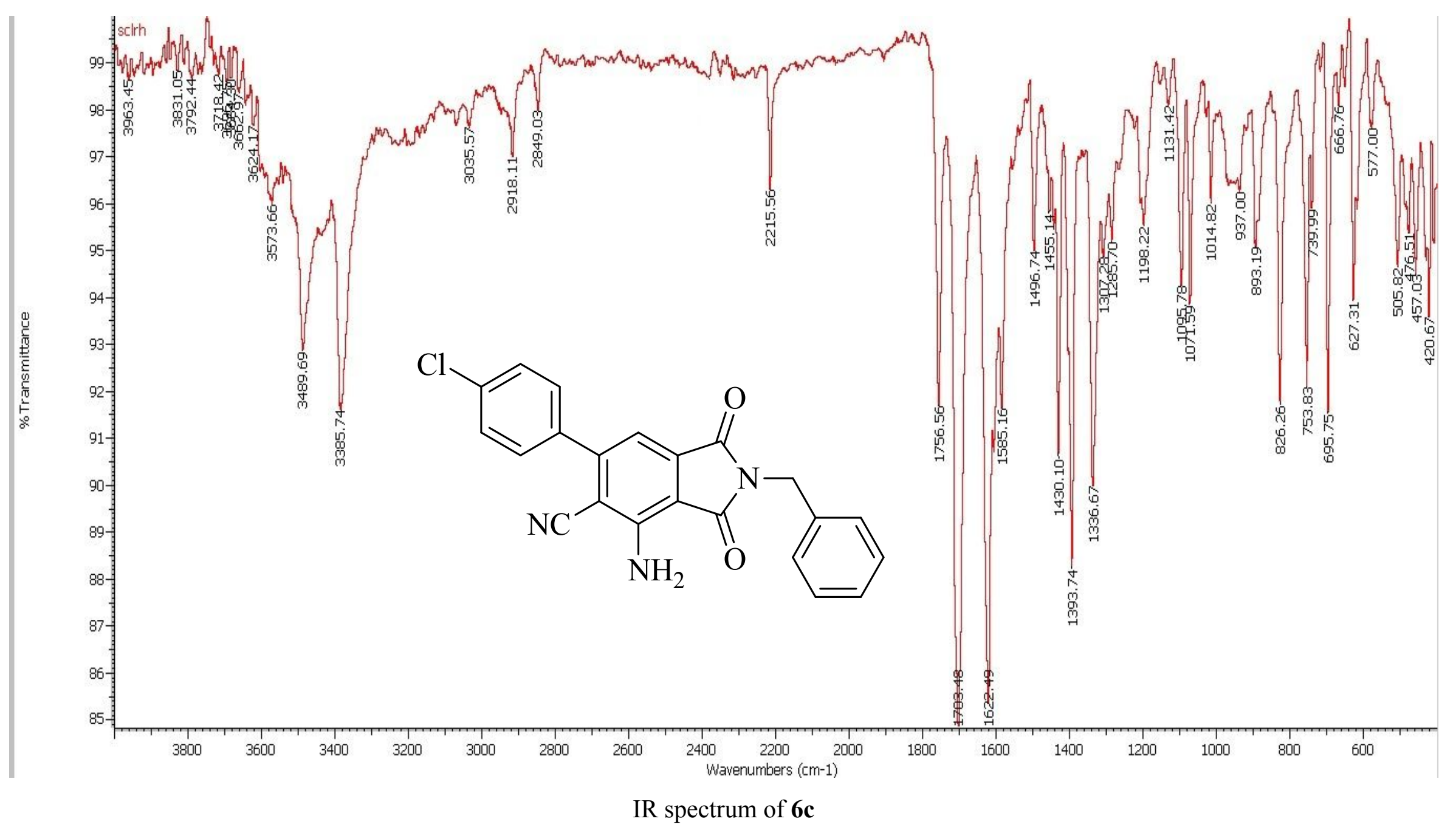




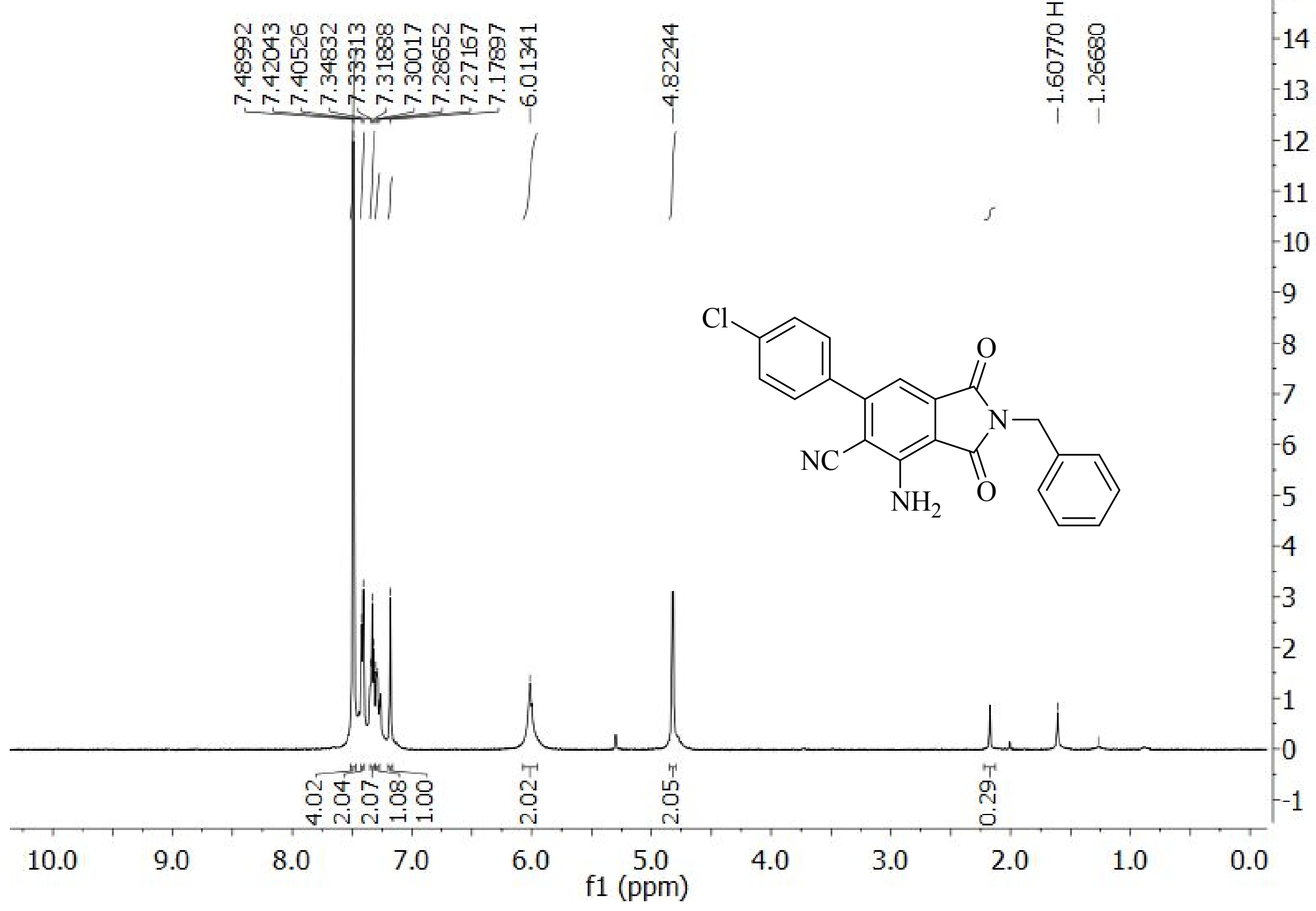

${ }^{1} \mathrm{H}$ NMR $\left(\mathrm{CDCl}_{3}, 500 \mathrm{MHz}\right)$ spectrum of $\mathbf{6 c}$ 


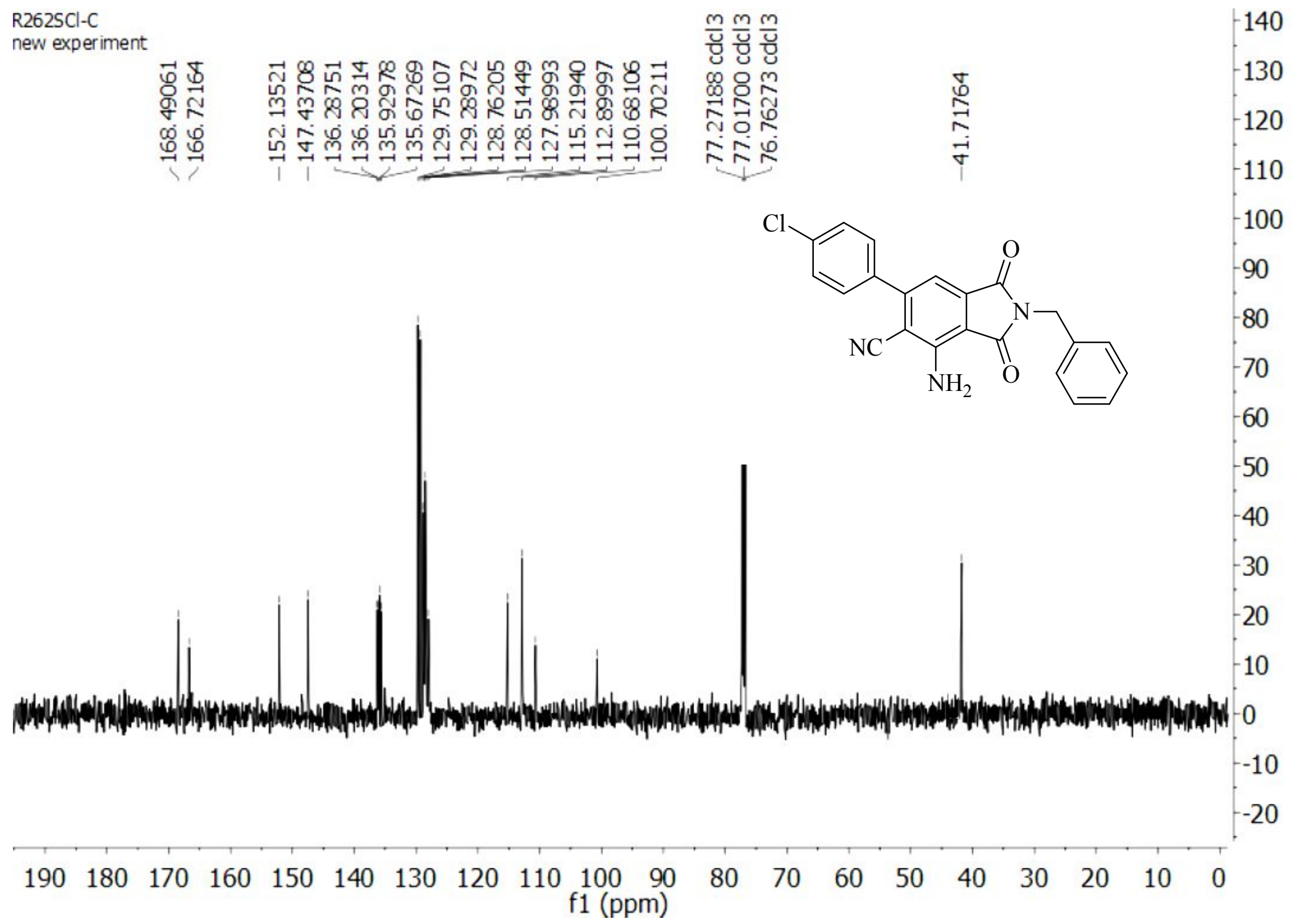

${ }^{13} \mathrm{C}\left\{{ }^{1} \mathrm{H}\right\}$ NMR $\left(\mathrm{CDCl}_{3}, 125 \mathrm{MHz}\right)$ spectrum of $\mathbf{6 c}$ 


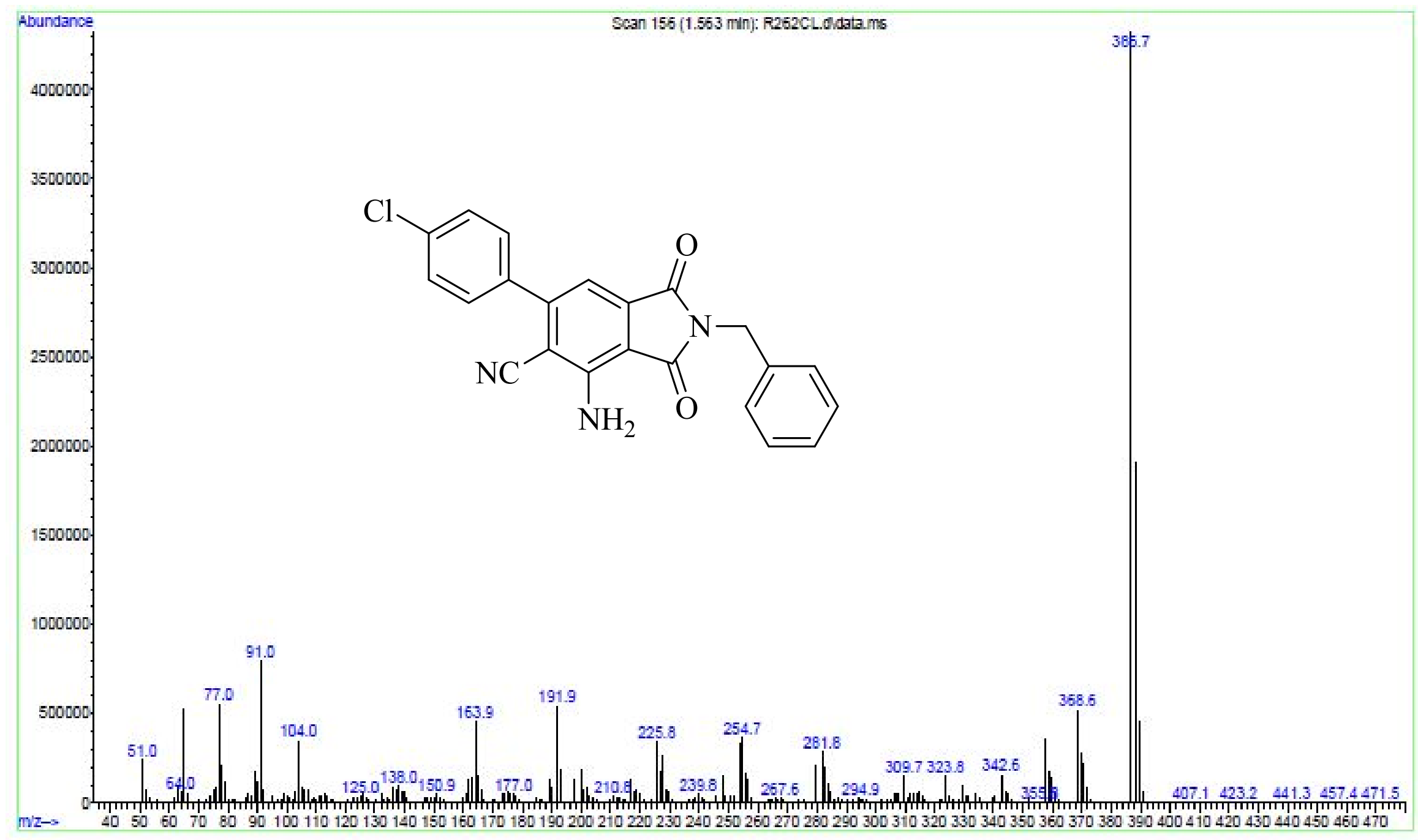

Mass spectrum of $\mathbf{6 c}$ 


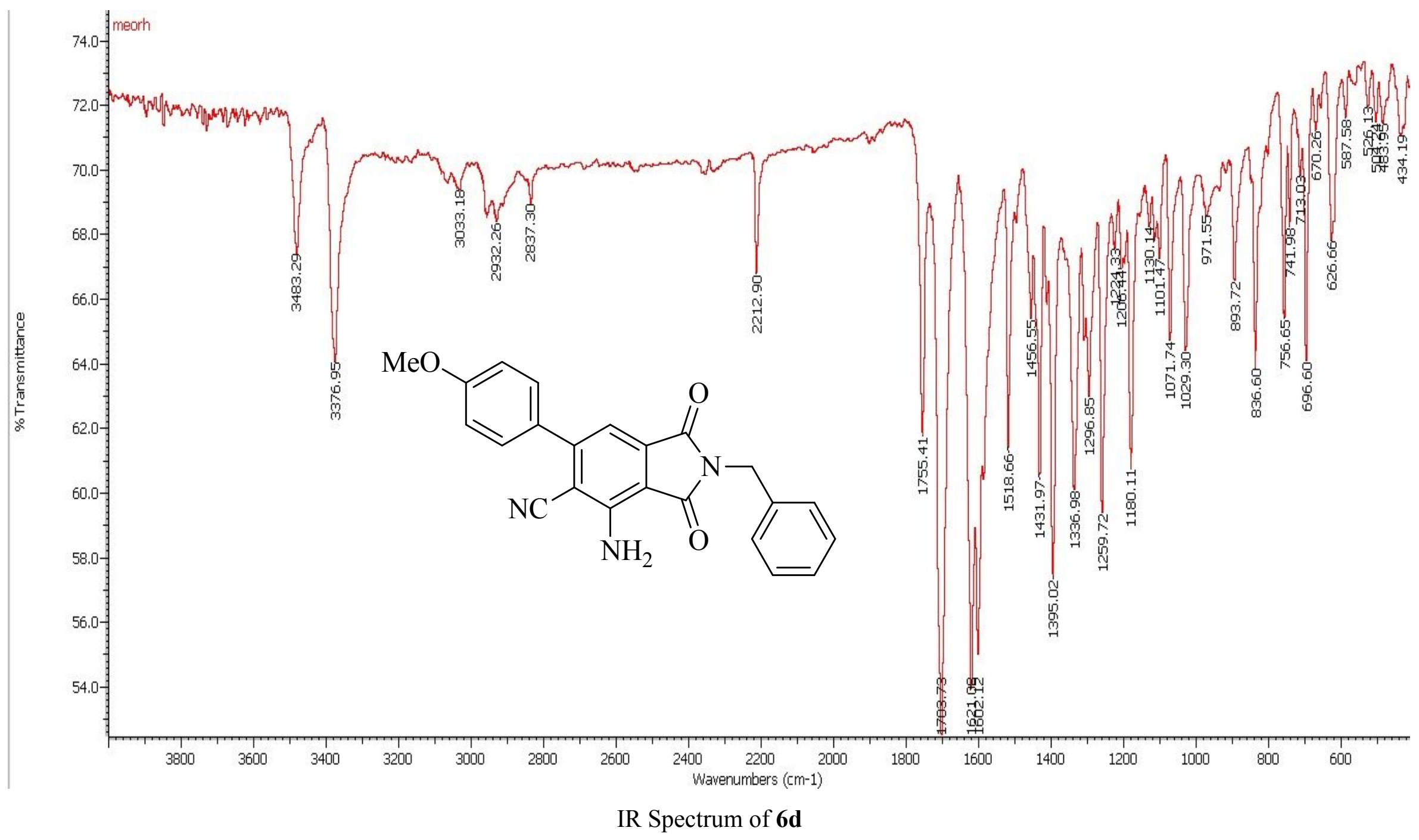




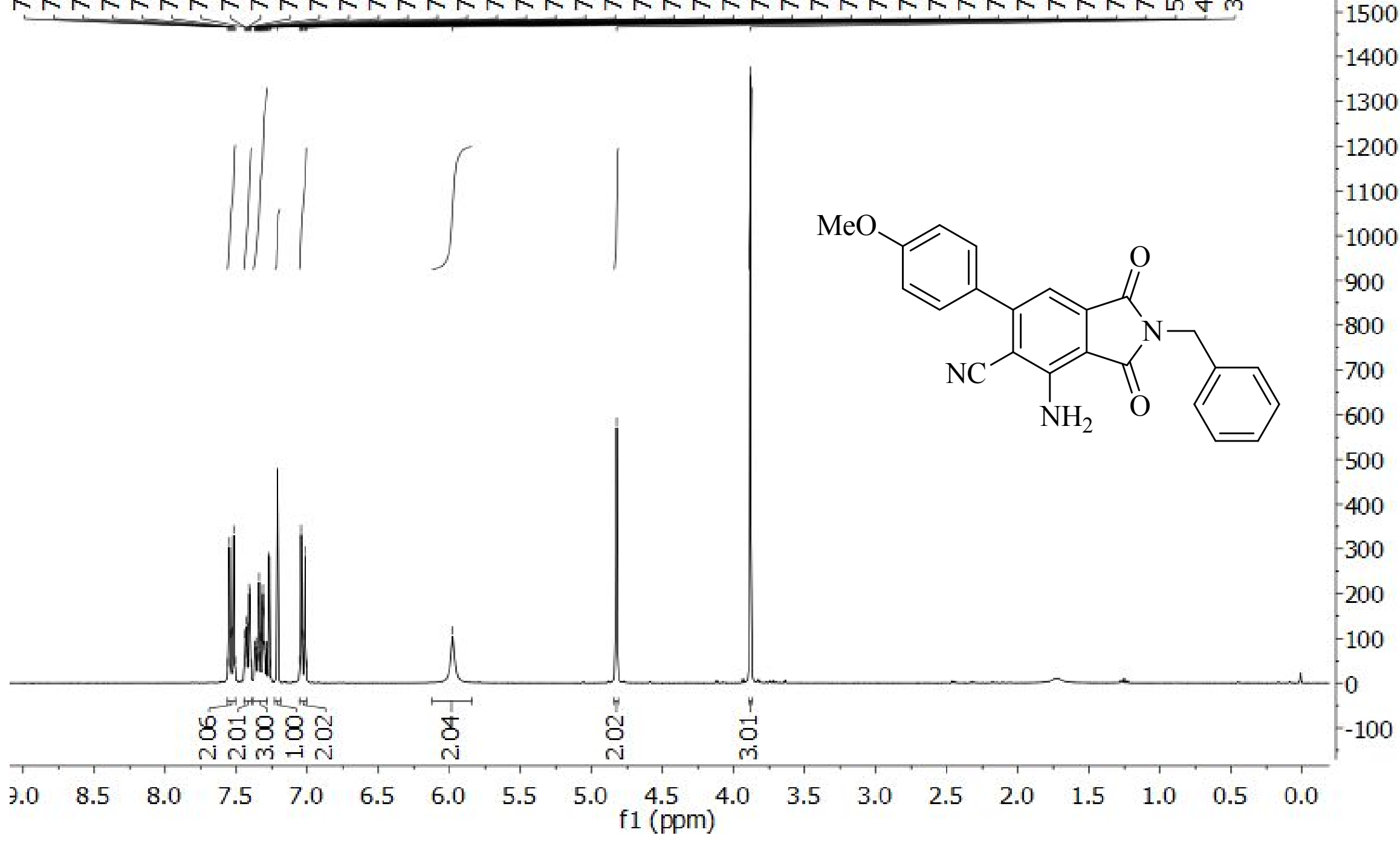

${ }^{1} \mathrm{H}$ NMR $\left(\mathrm{CDCl}_{3}, 300 \mathrm{MHz}\right)$ spectrum of $\mathbf{6 d}$ 


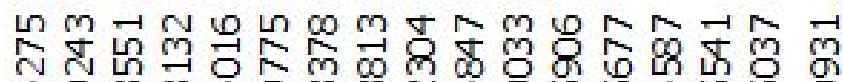
ซ ชิ

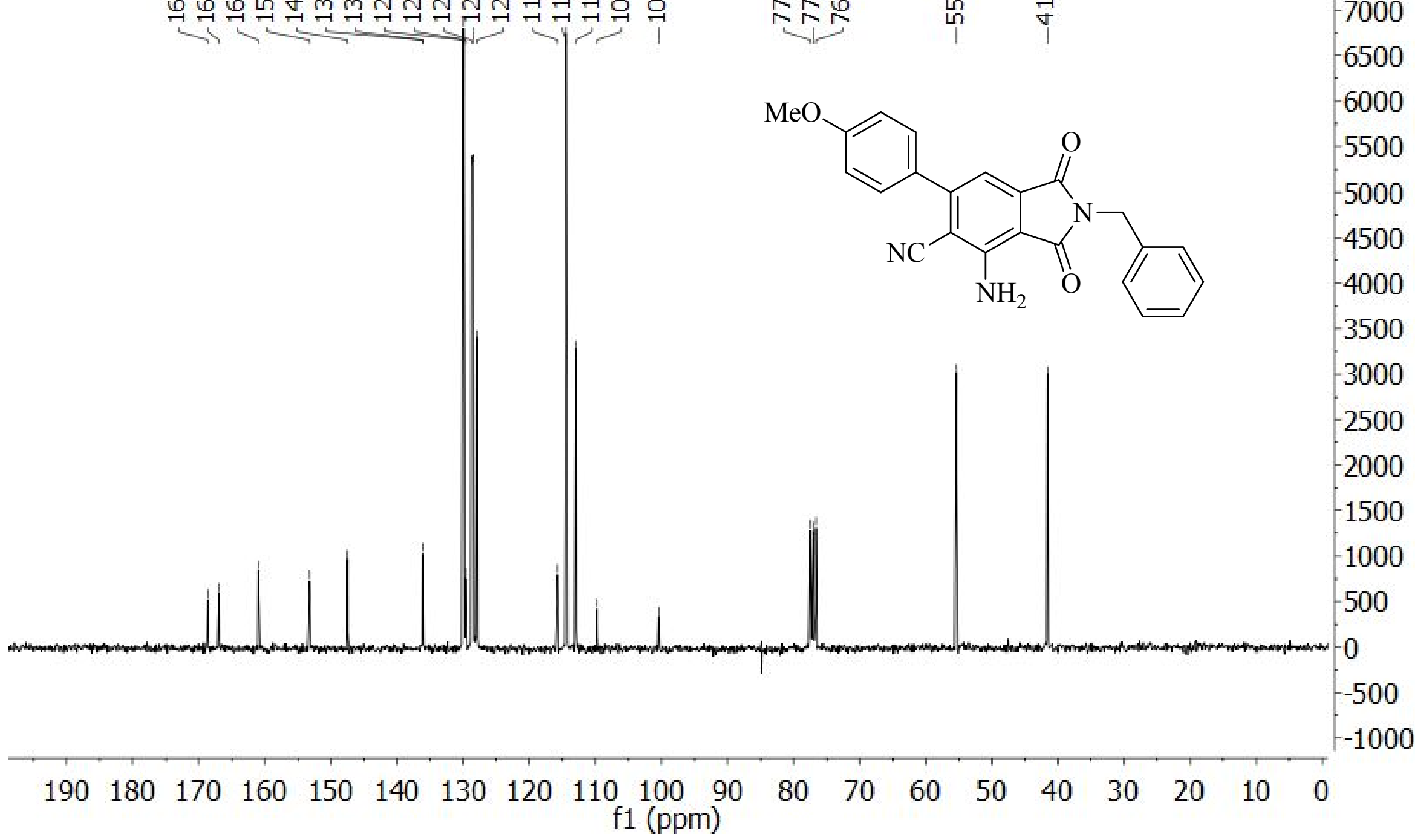

${ }^{13} \mathrm{C}\left\{{ }^{1} \mathrm{H}\right\} \mathrm{NMR}\left(\mathrm{CDCl}_{3}, 75 \mathrm{MHz}\right)$ spectrum of $\mathbf{6 d}$ 


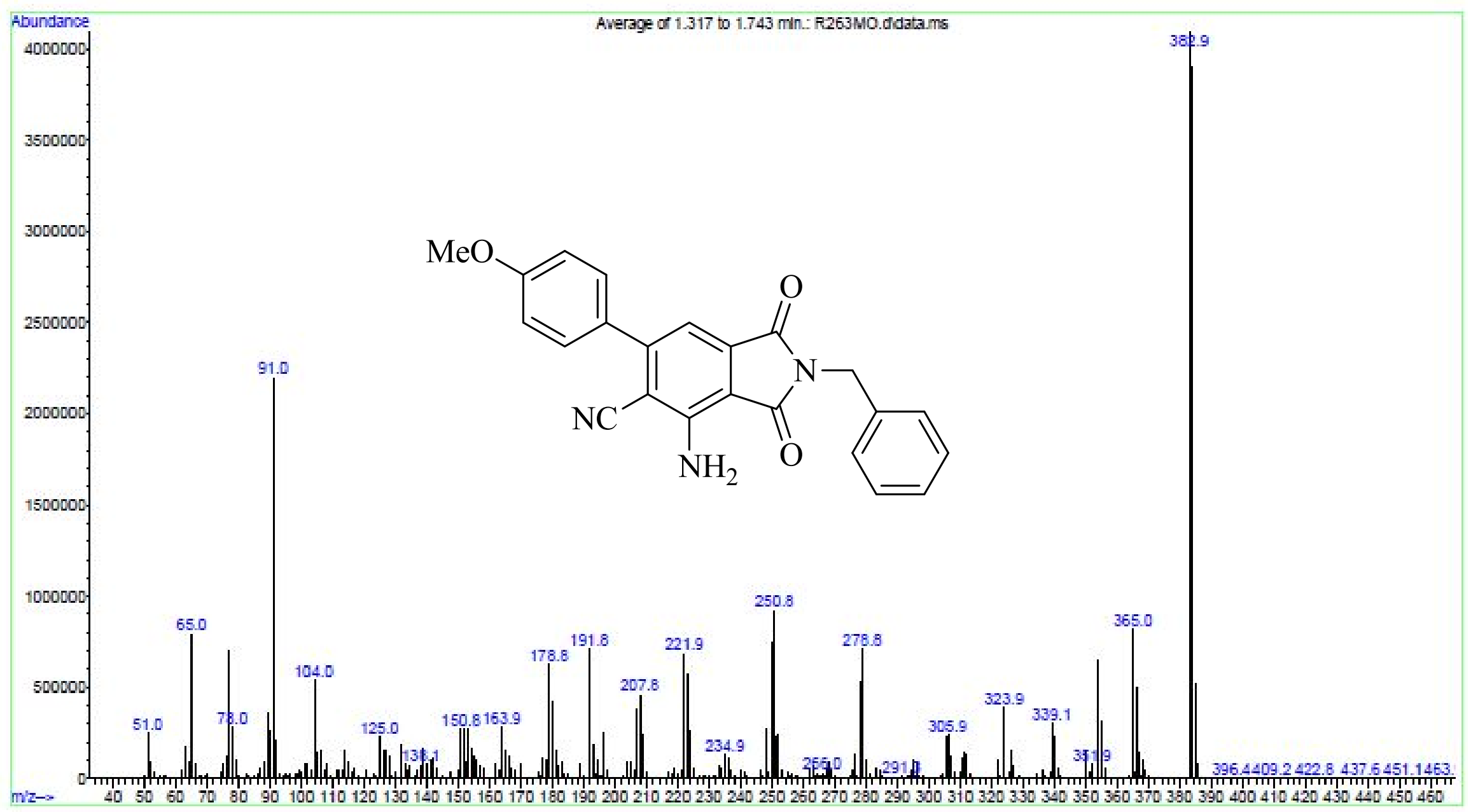

Mass Spectrum of $\mathbf{6 d}$ 


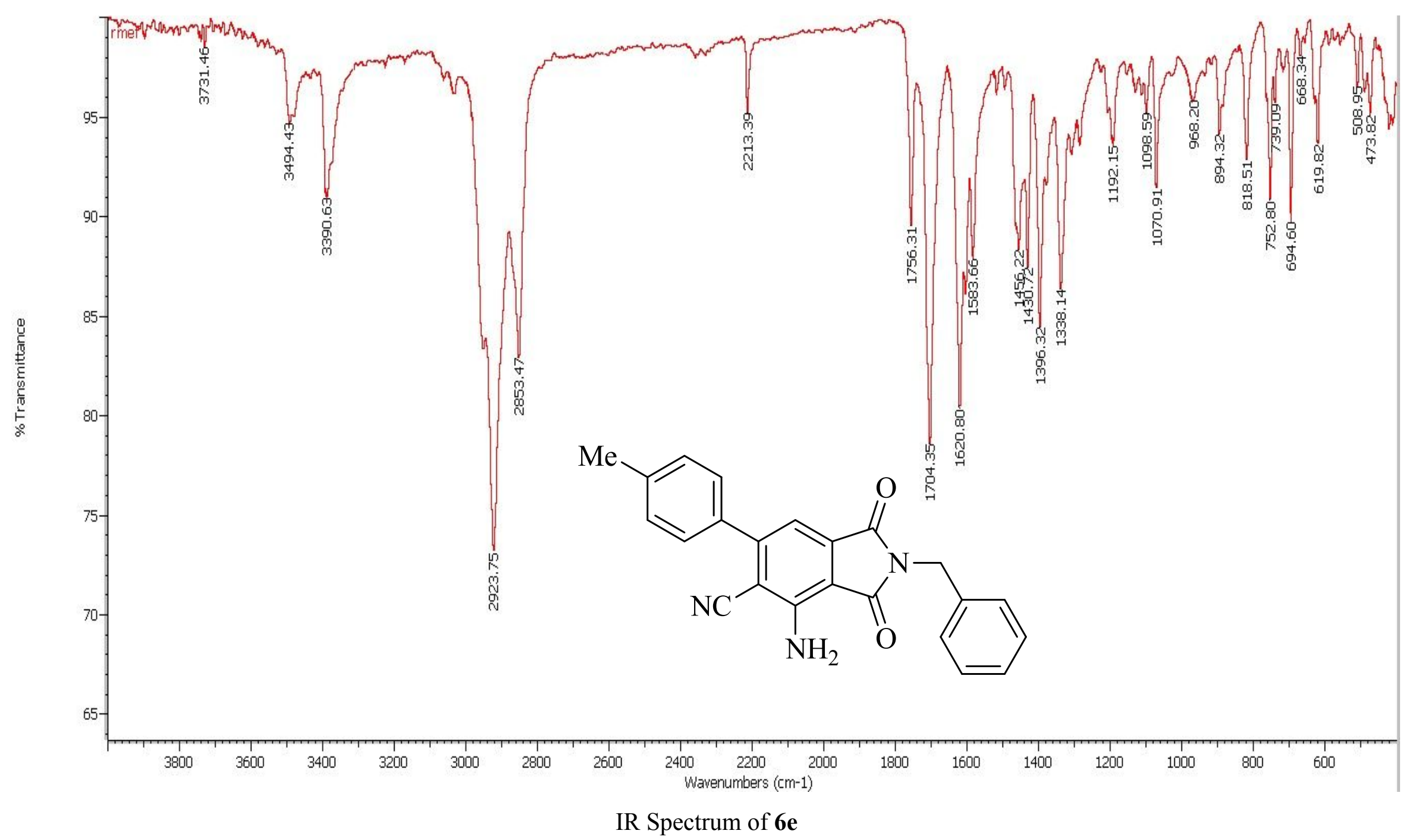




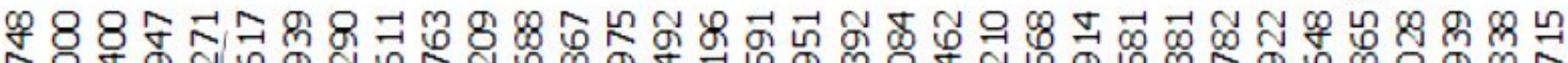

क

g.

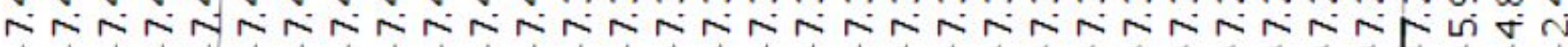

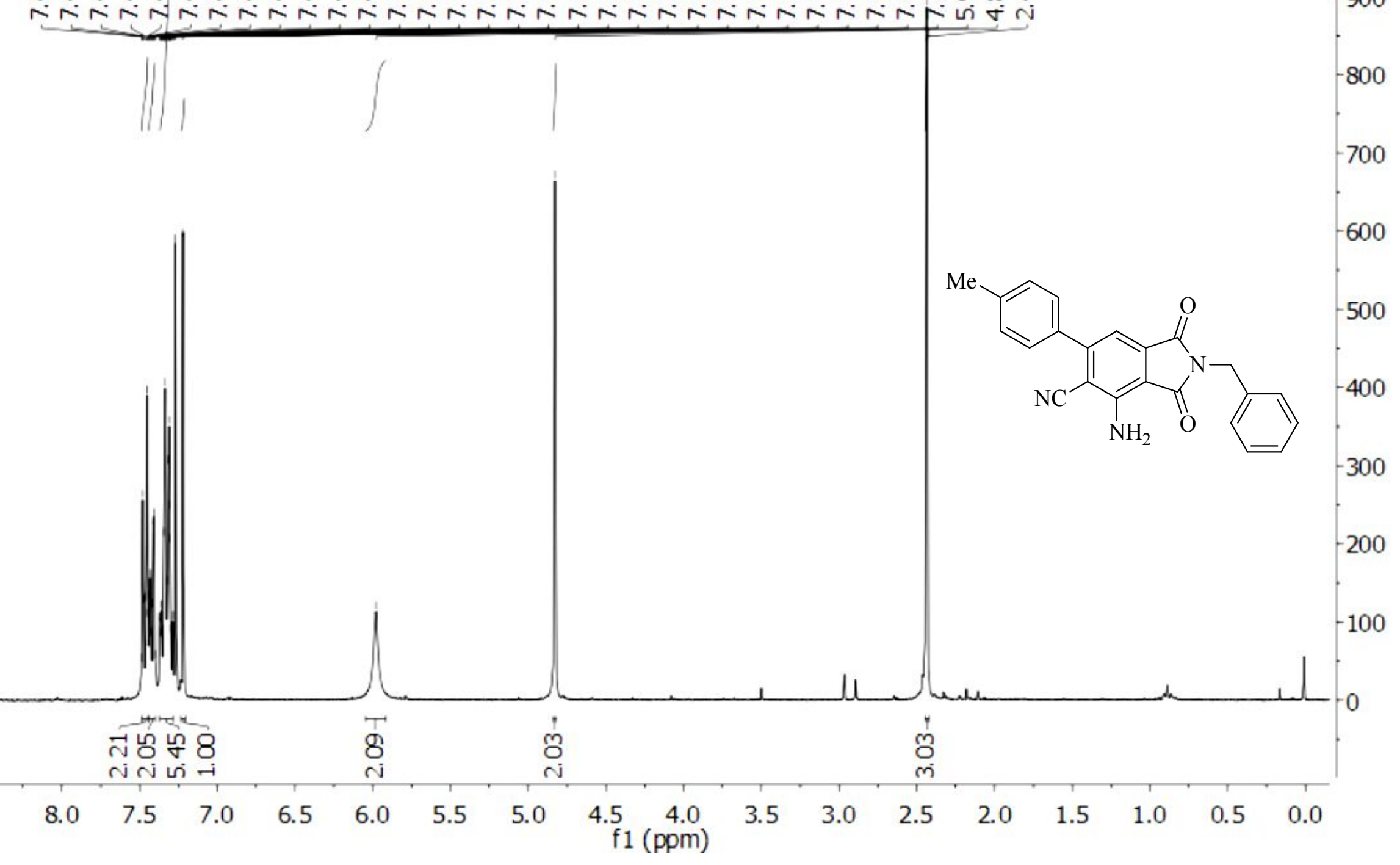

${ }^{1} \mathrm{H} \mathrm{NMR}\left(\mathrm{CDCl}_{3}, 300 \mathrm{MHz}\right)$ spectrum of $\mathbf{6 e}$ 


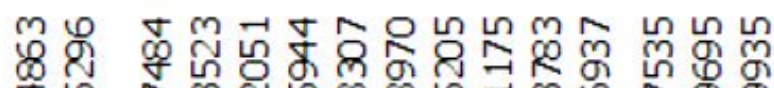

它

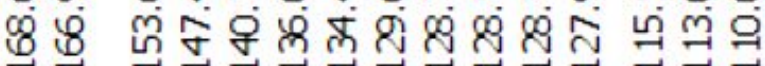

$\stackrel{\mathrm{g}}{\mathrm{m}}$

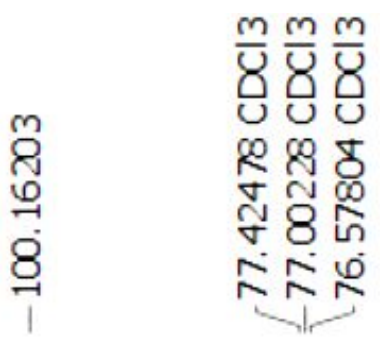

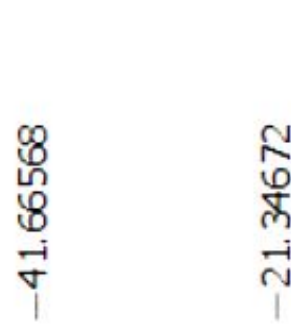

$-7500$

7000

$-6500$

$-6000$

$-5500$

5000

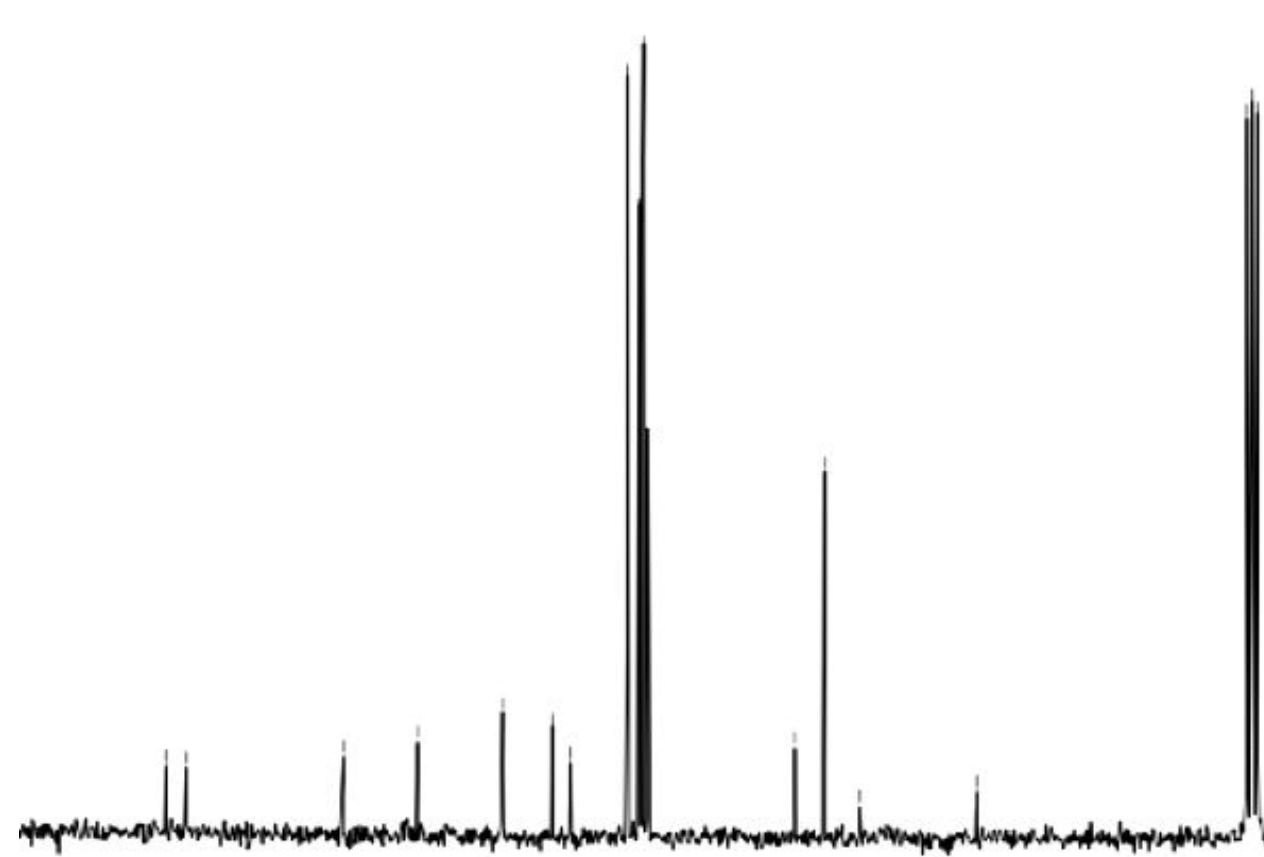

Me

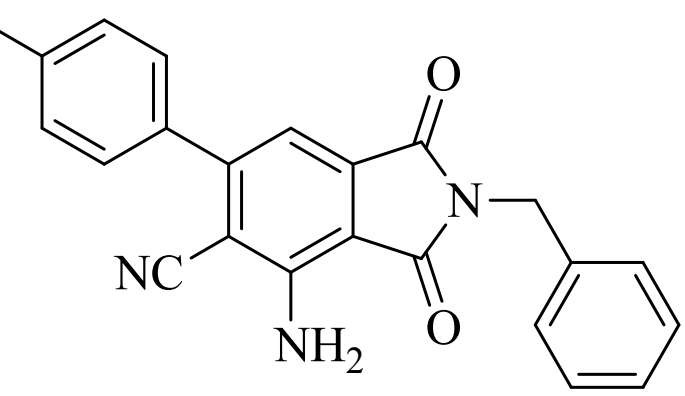

$-4500$

4000

$-3500$

$-3000$

$-2500$

$-2000$

1500

$-1000$

500

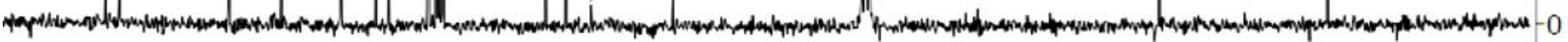




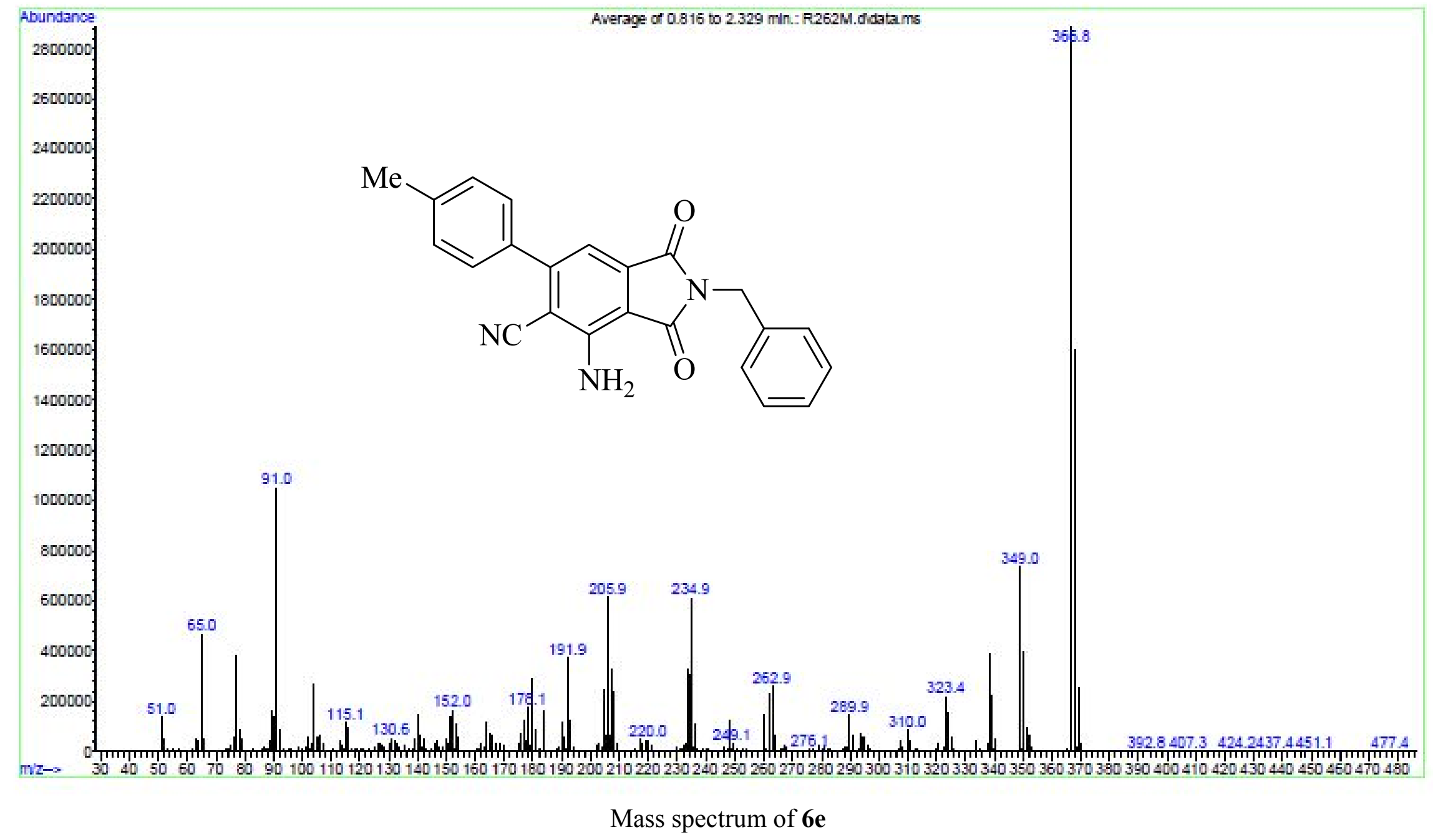




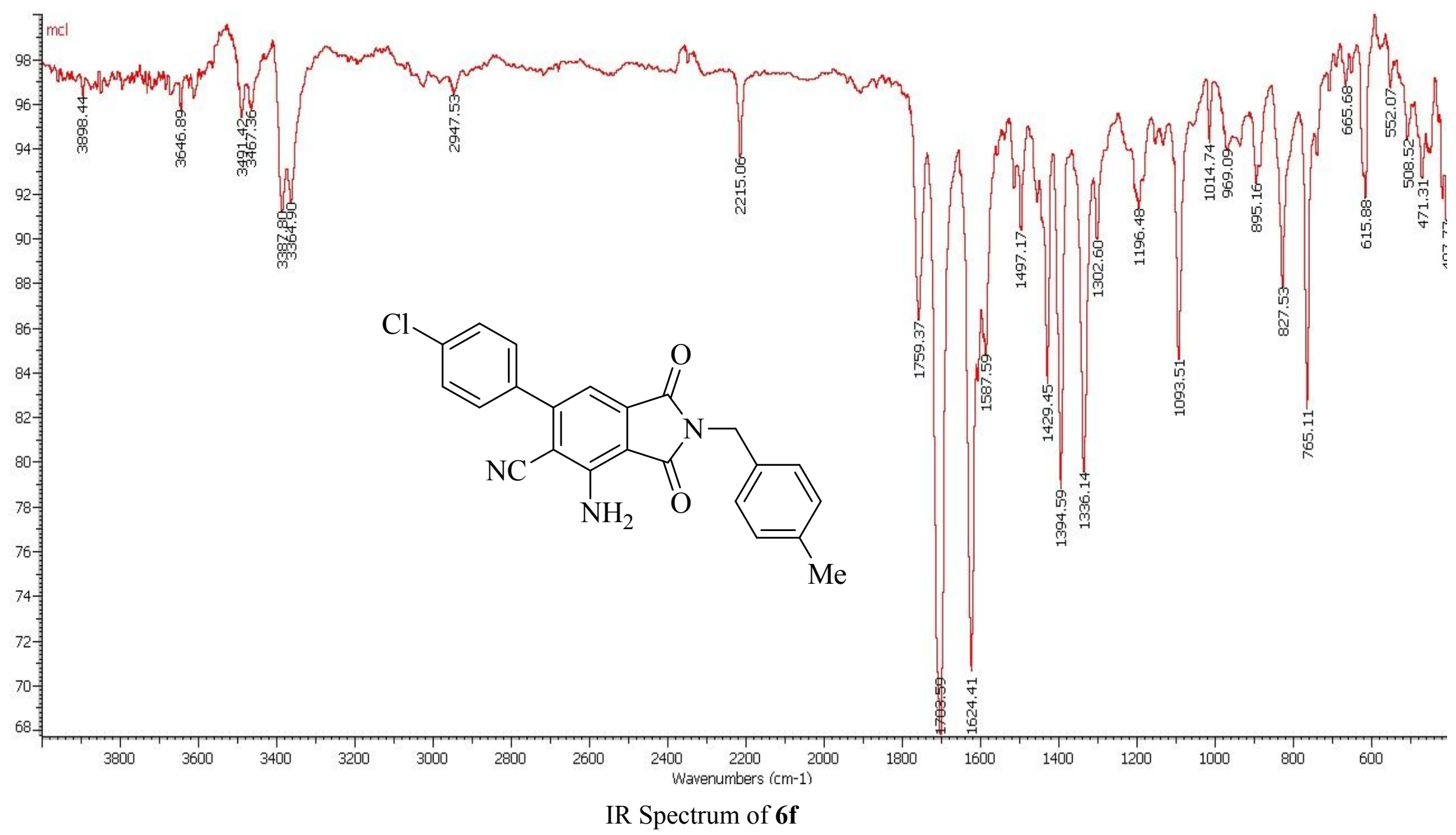




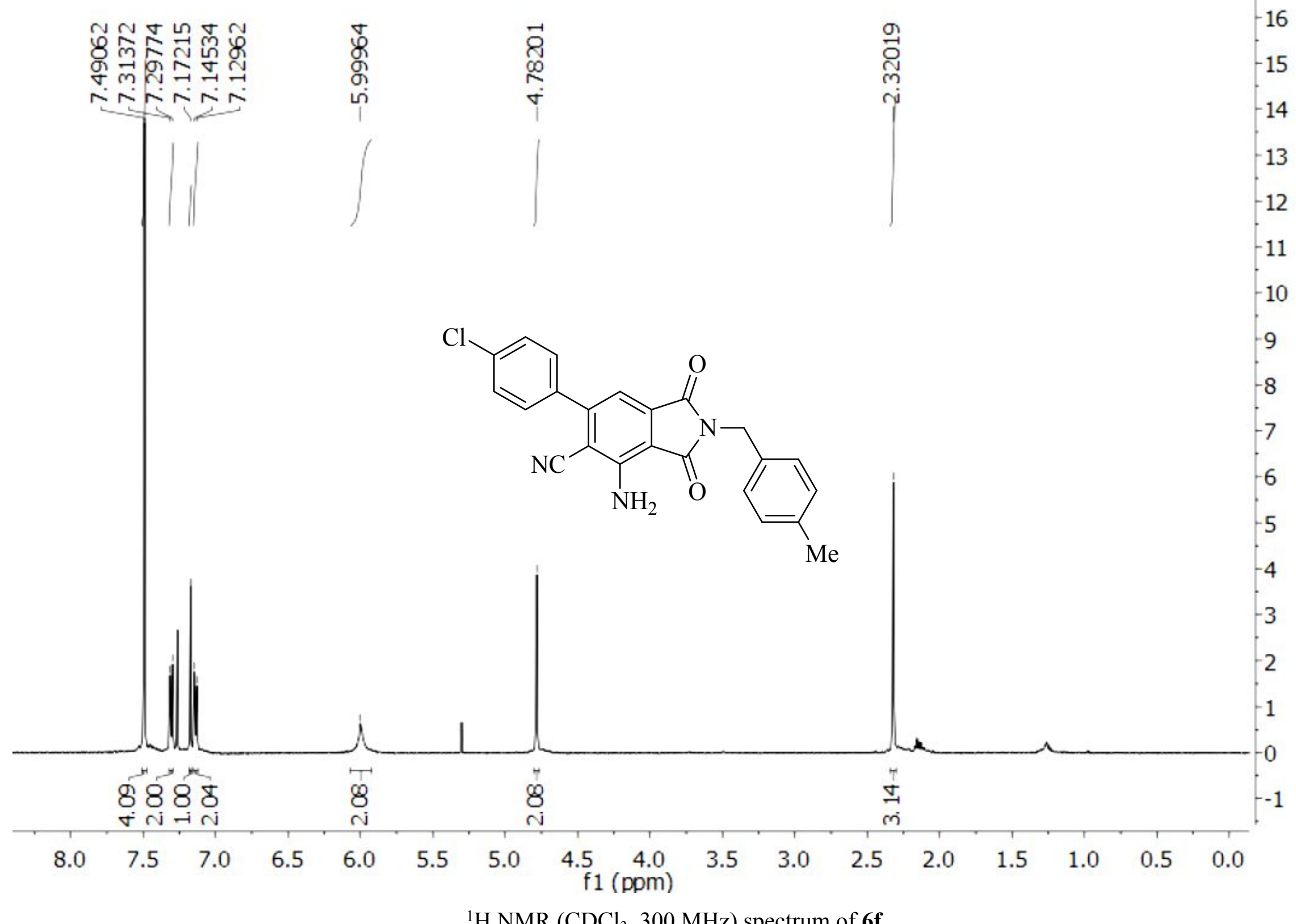

${ }^{1} \mathrm{H}$ NMR $\left(\mathrm{CDCl}_{3}, 300 \mathrm{MHz}\right)$ spectrum of $\mathbf{6 f}$ 
R262med-C

new experiment

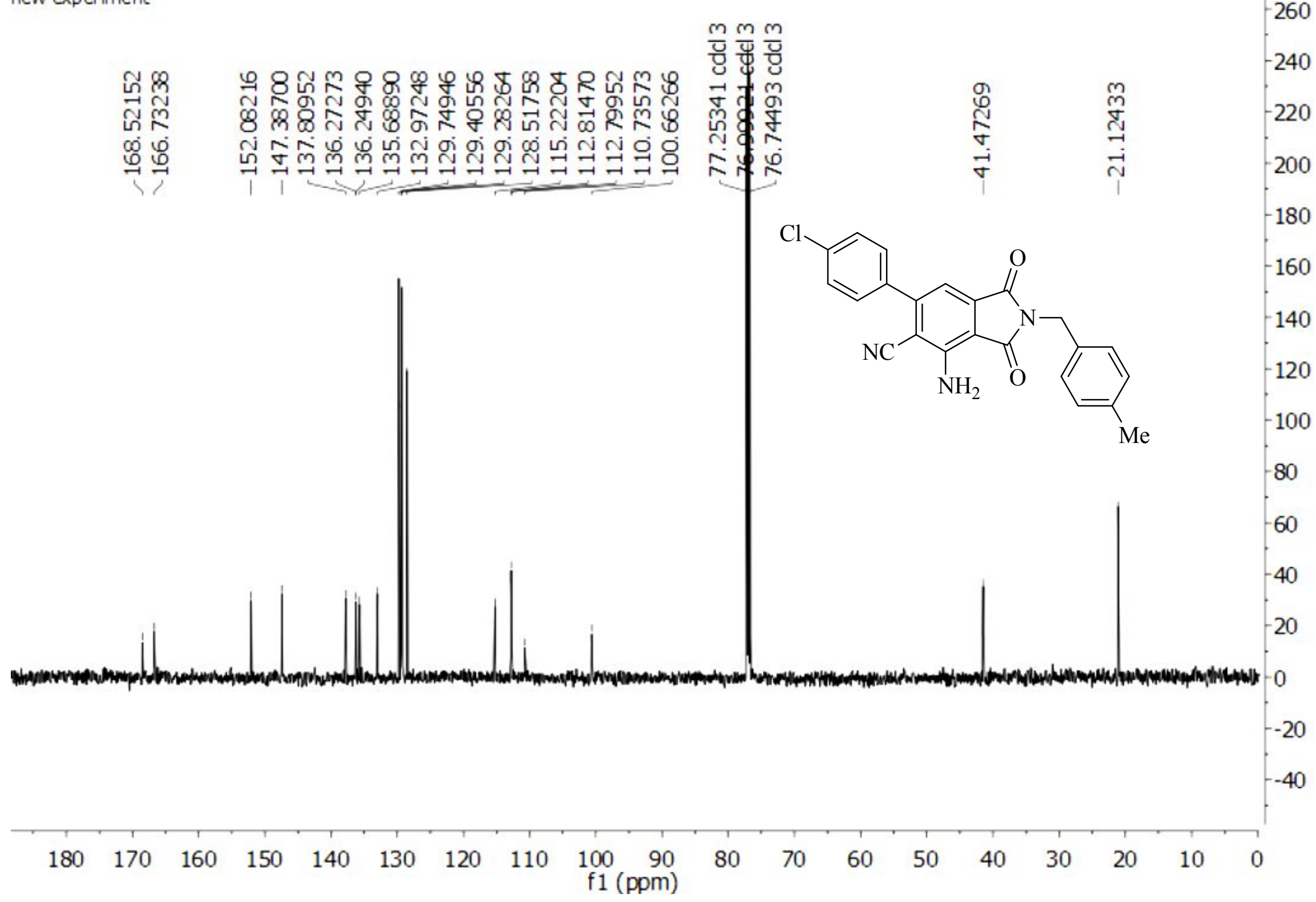

${ }^{13} \mathrm{C}\left\{{ }^{1} \mathrm{H}\right\}$ NMR $\left(\mathrm{CDCl}_{3}, 125 \mathrm{MHz}\right)$ spectrum of $\mathbf{6 f}$ 


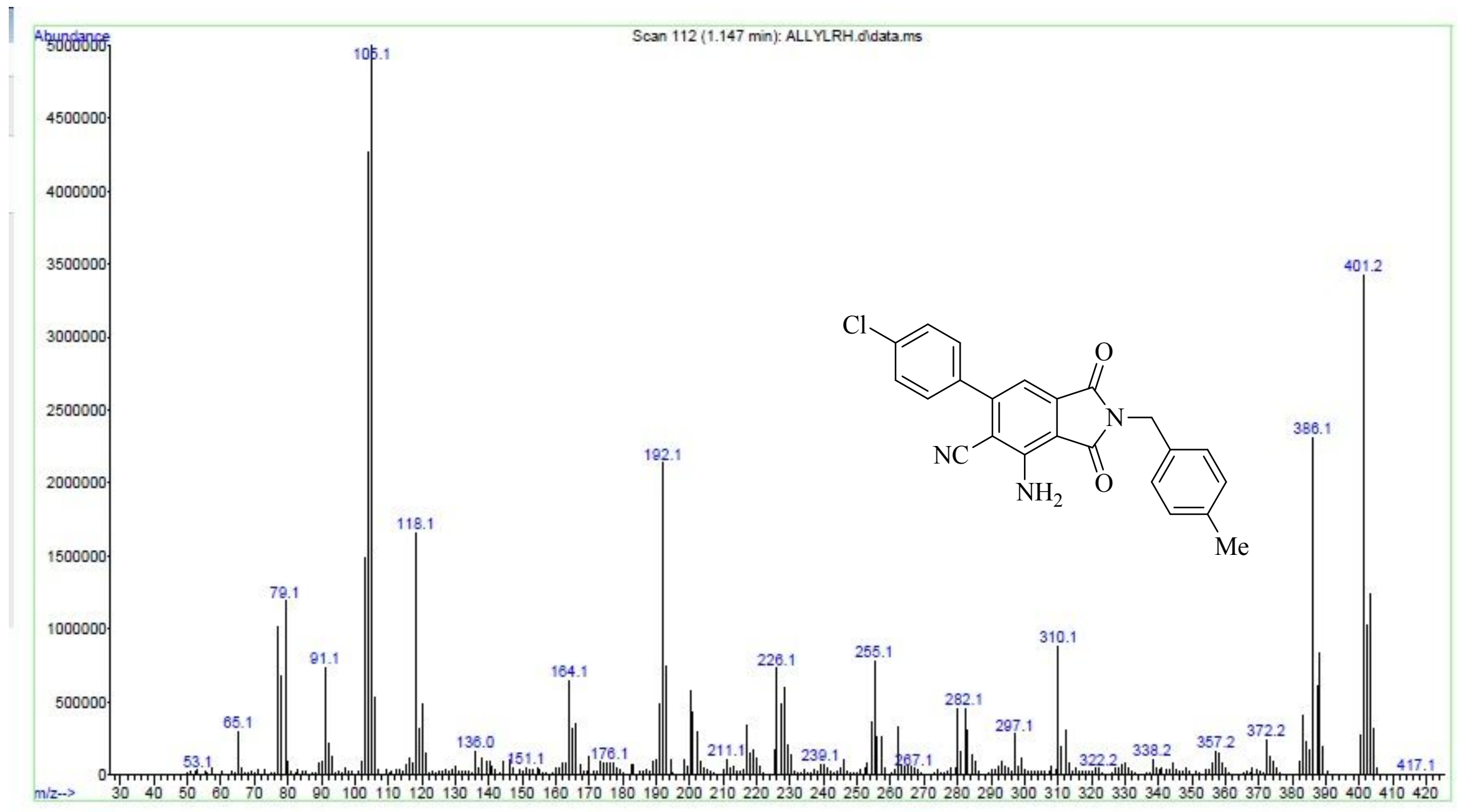

Mass Spectrum of $\mathbf{6} \mathbf{f}$ 


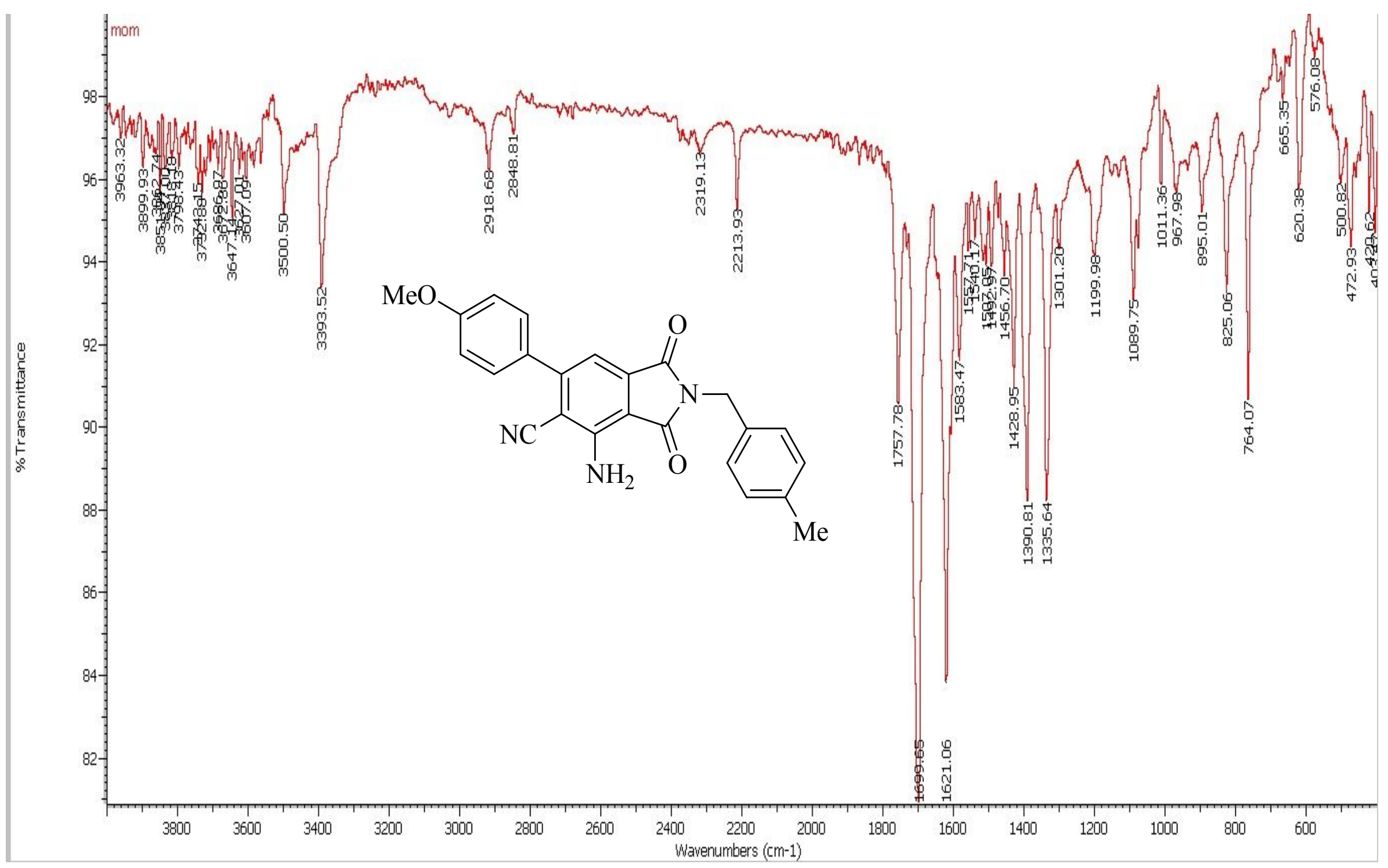

IR Spectrum of $\mathbf{6 g}$ 
new experiment 웜 $\mathrm{N}$ 은

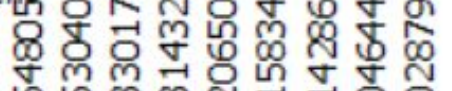
เก กุ m rinariana

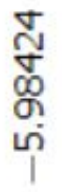
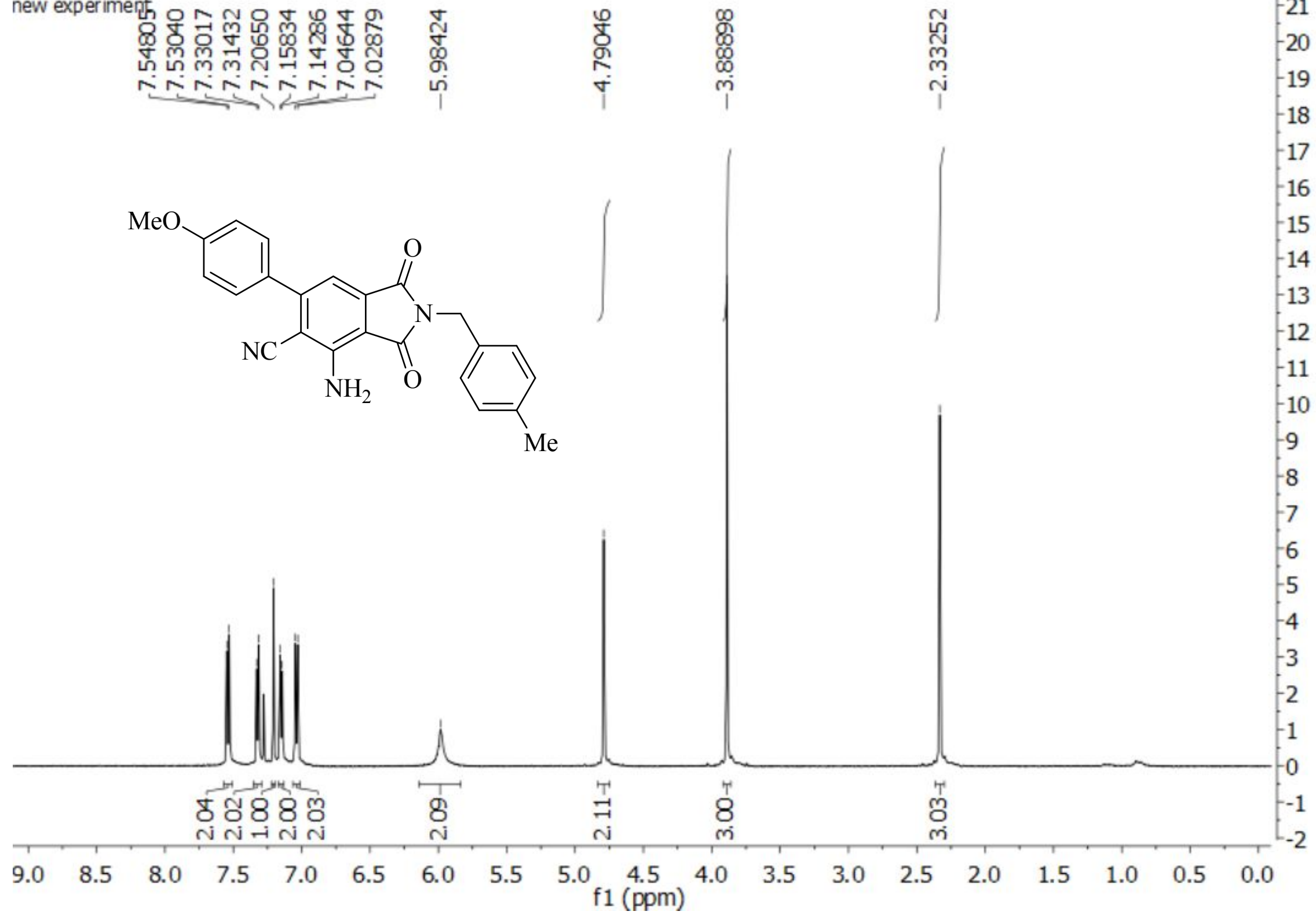

${ }^{1} \mathrm{H} \mathrm{NMR}\left(\mathrm{CDCl}_{3}, 500 \mathrm{MHz}\right)$ spectrum of $\mathbf{6 g}$ 
RMBMO-C

new experiment

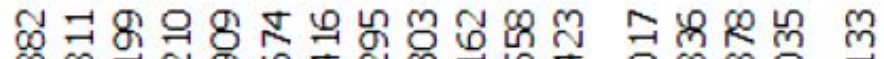

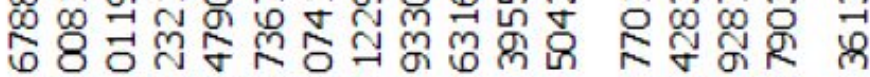
它


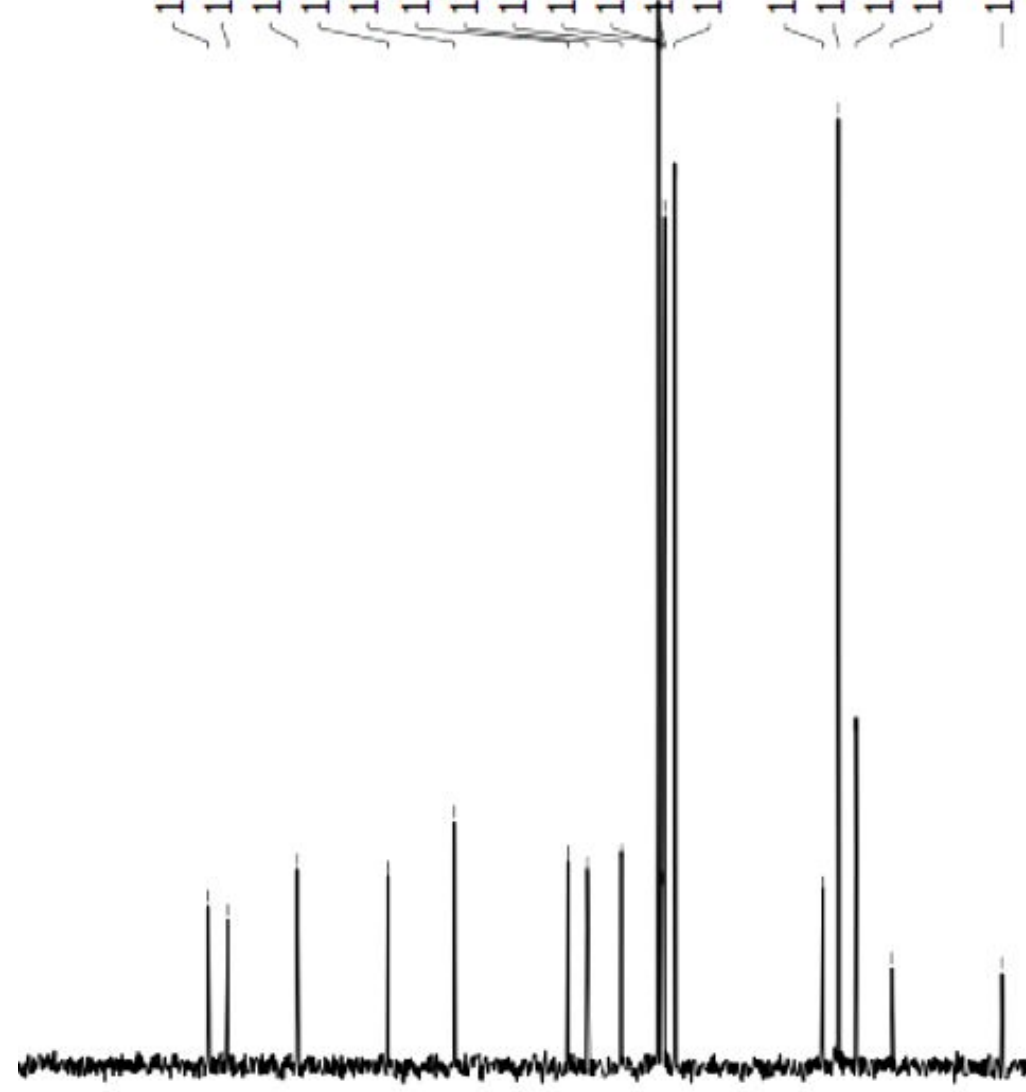

$\frac{m}{y} \frac{m}{y}$

उु

$\infty$ ஸก

हैं

NON

会会

2n

্ֻলু

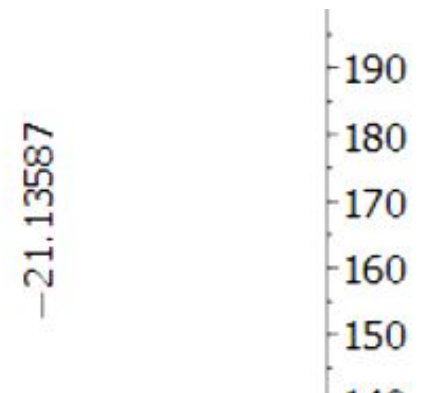

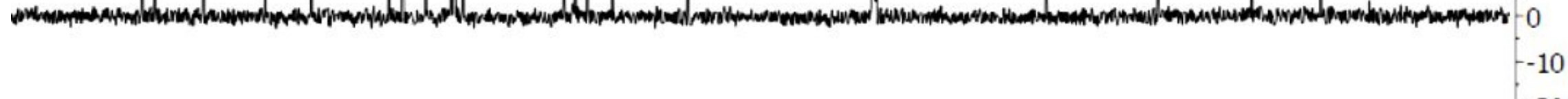




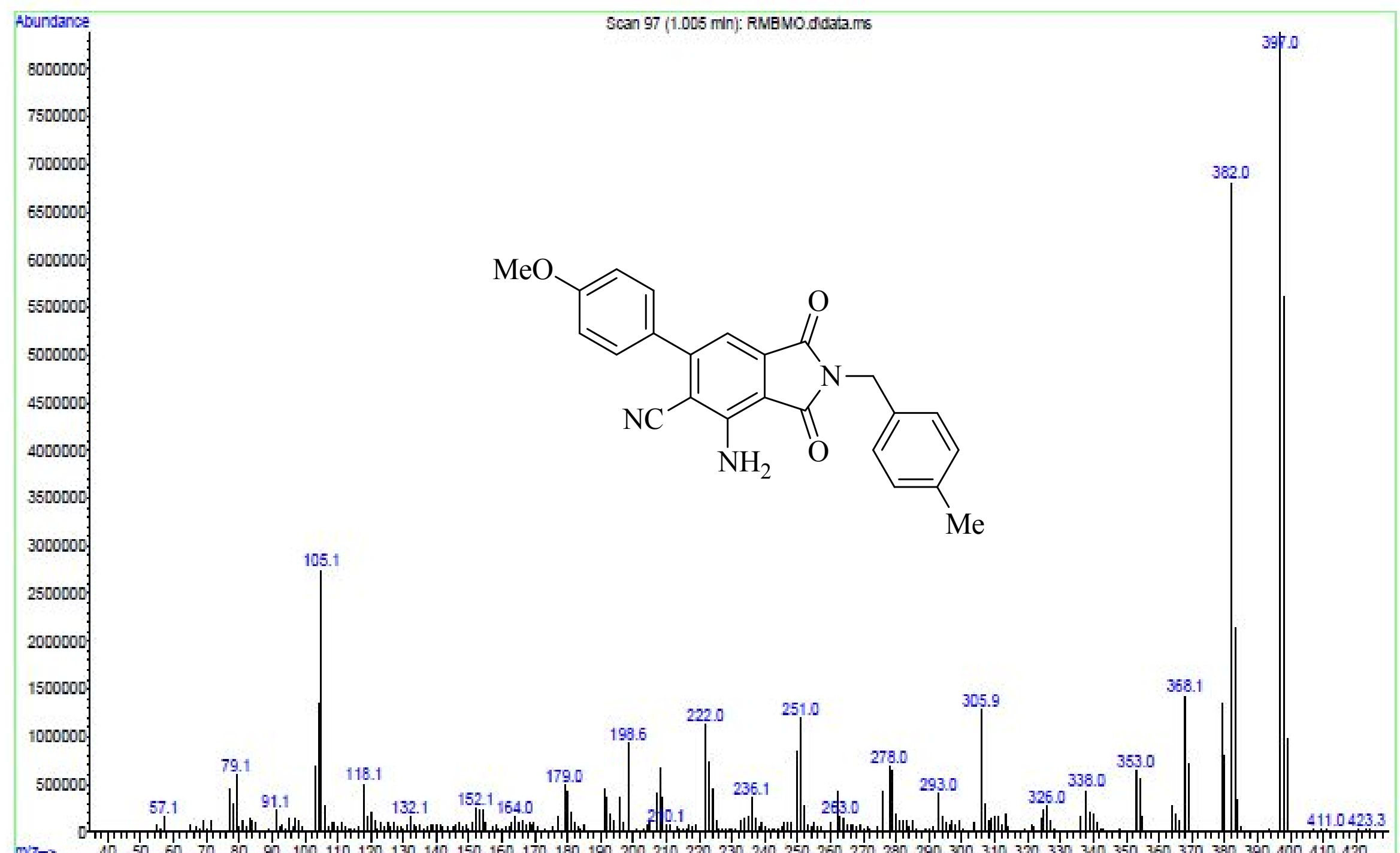

$\mathrm{m} V \mathrm{z}=\mathrm{>}$ $40 \quad 50 \quad 60 \quad 70 \quad 80 \quad 90100110120130140150160170180190200210220230240250260270280290300310320330340350360370380390400410420$

Mass Spectrum of $\mathbf{6 g}$ 


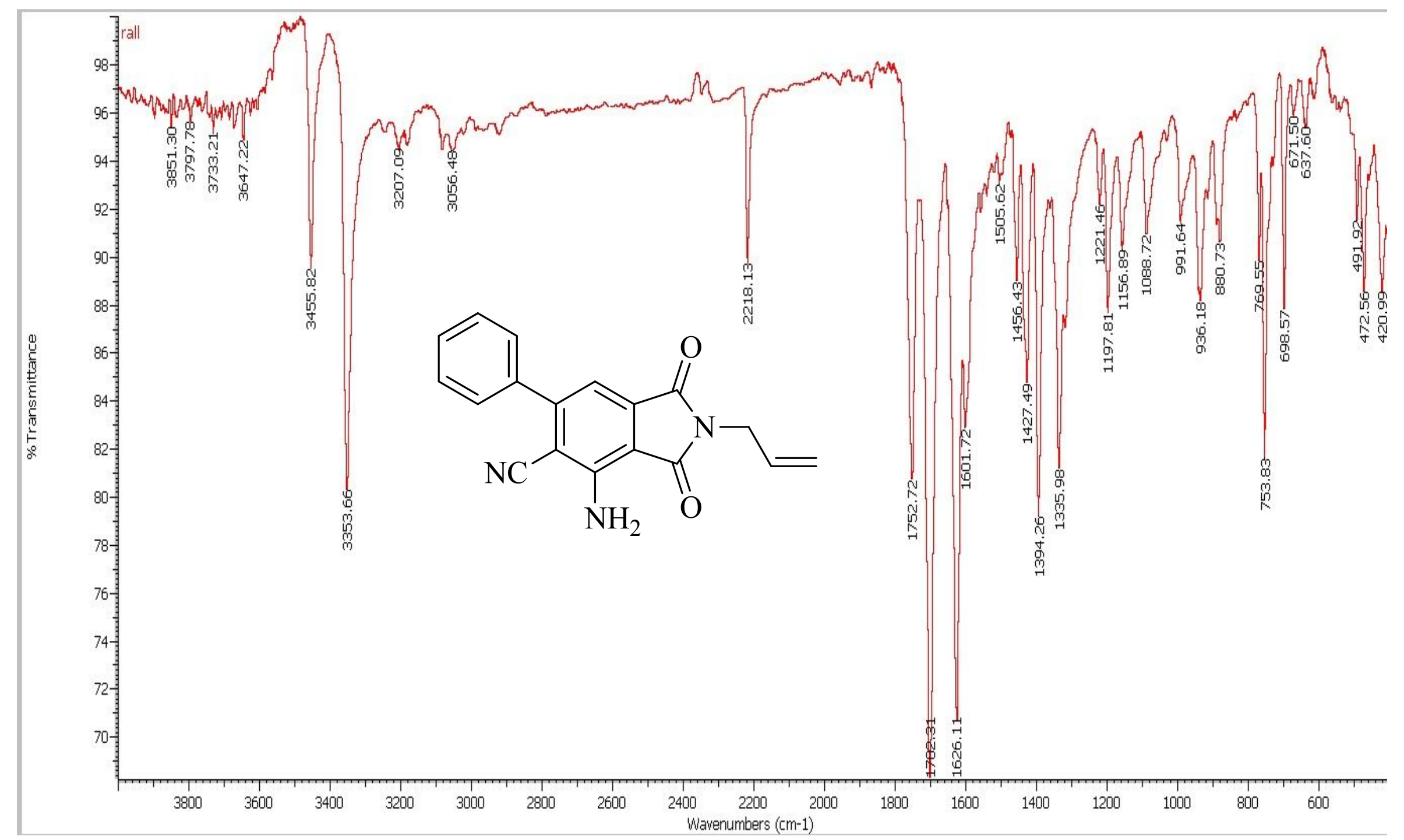

IR Spectrum of $\mathbf{6 h}$ 
늠

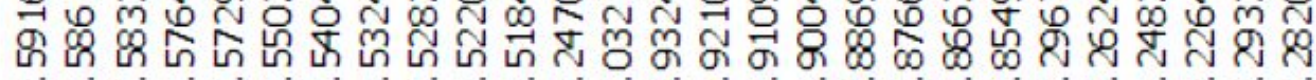

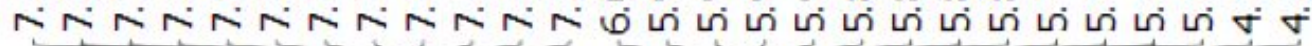
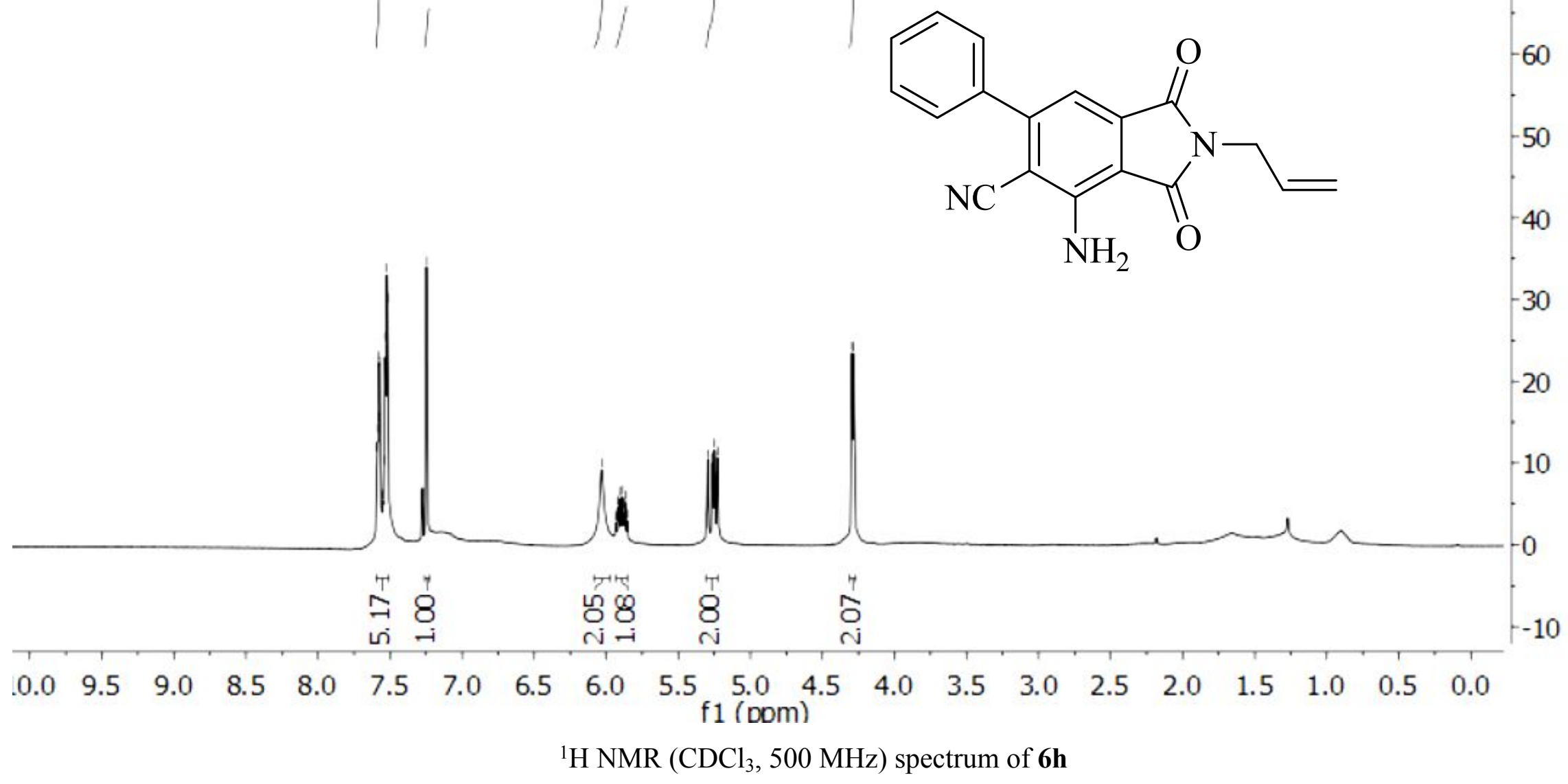
Rํำ

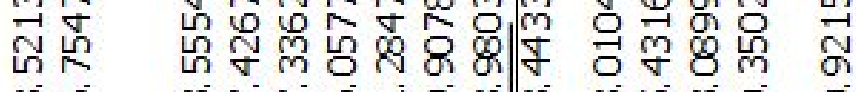

品

\& $\operatorname{m~}_{0} 8$

$\min$

0
0
0
0
$\stackrel{9}{0}$
$\dot{+}$

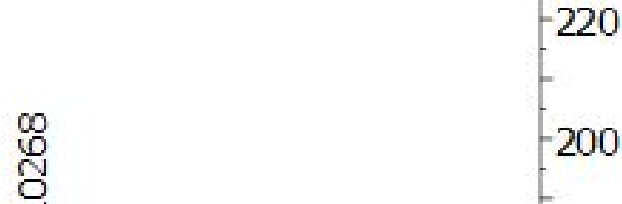

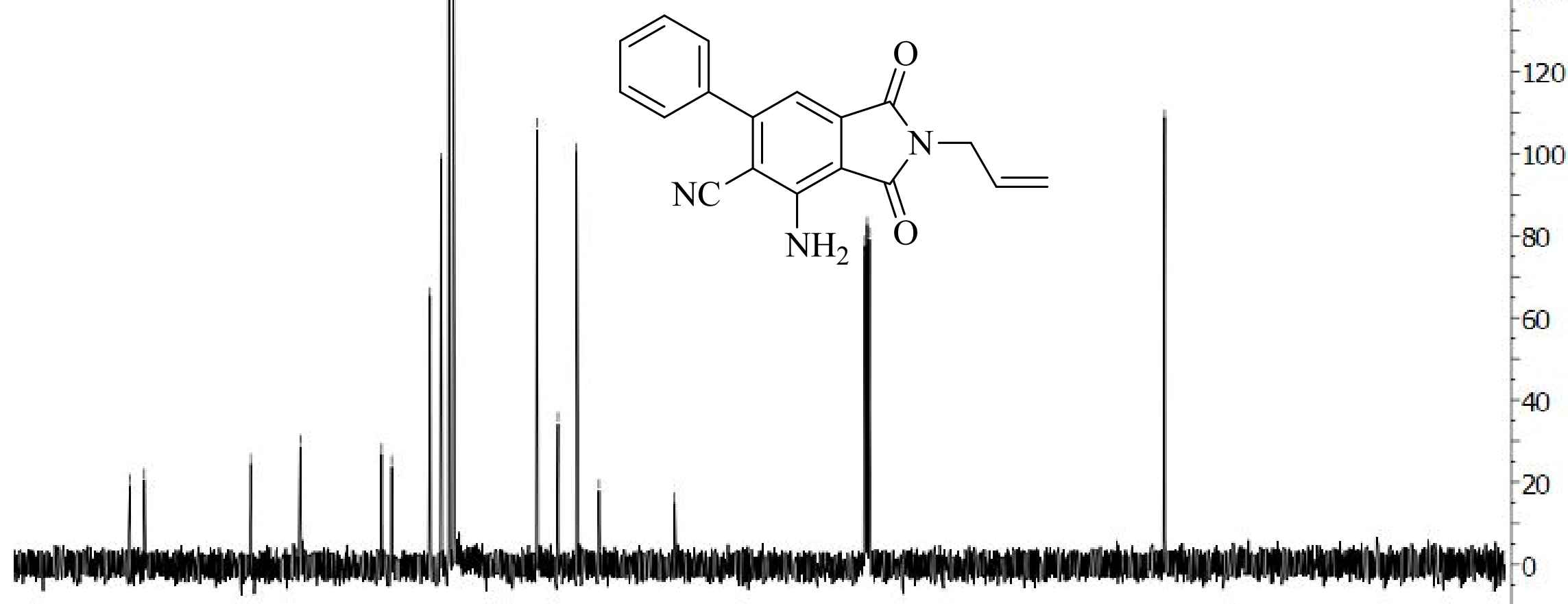




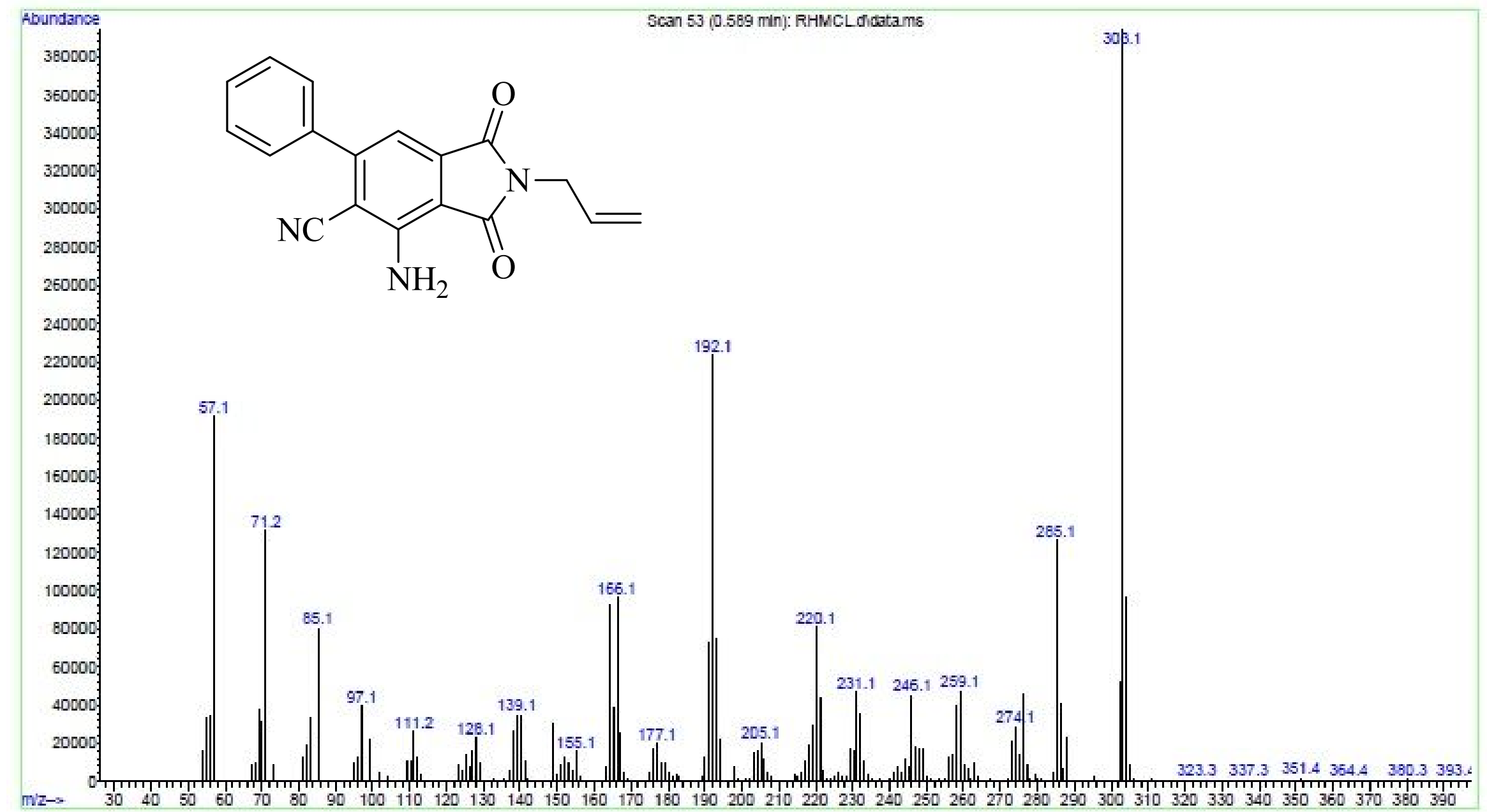

Mass spectrum of $\mathbf{6 h}$ 


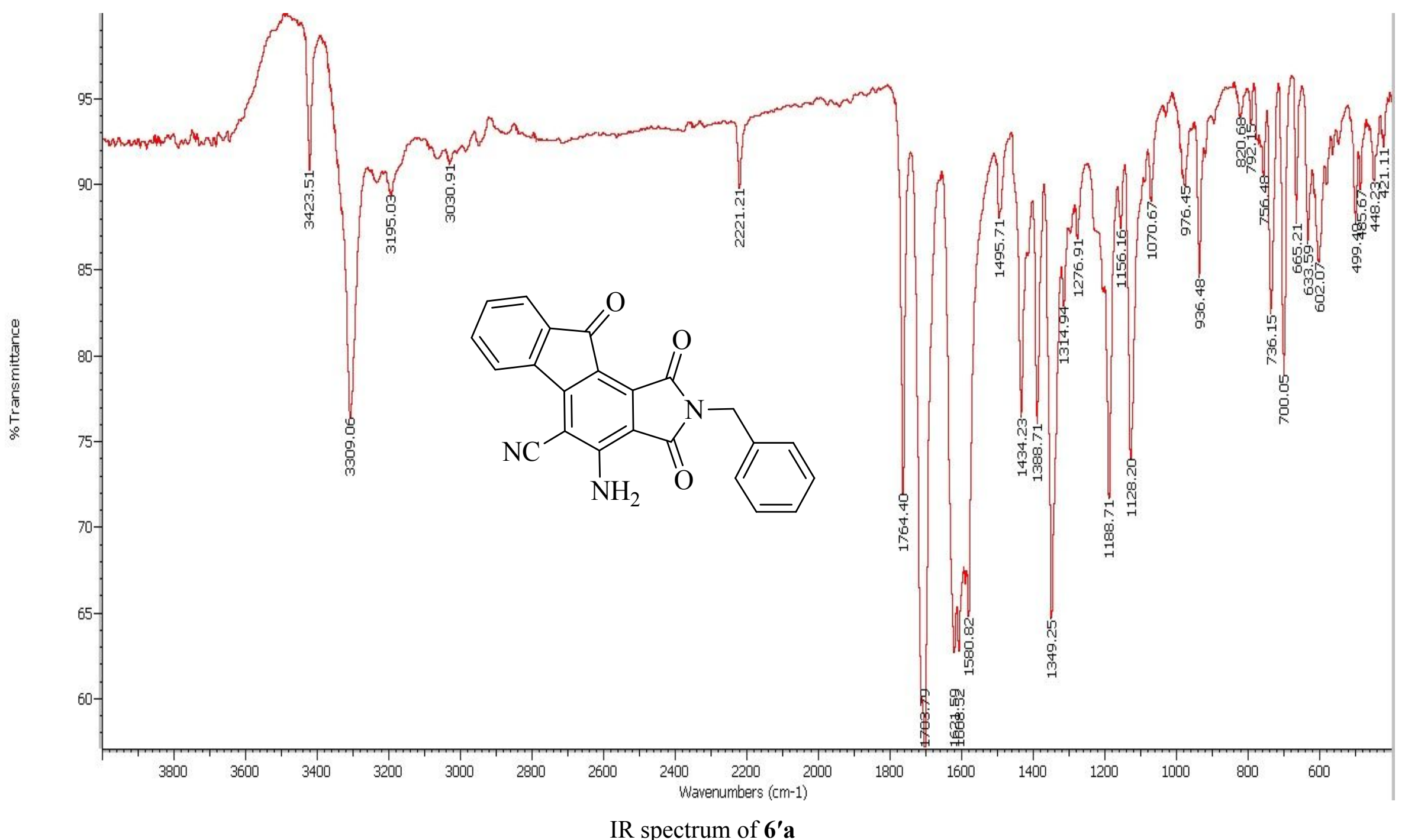




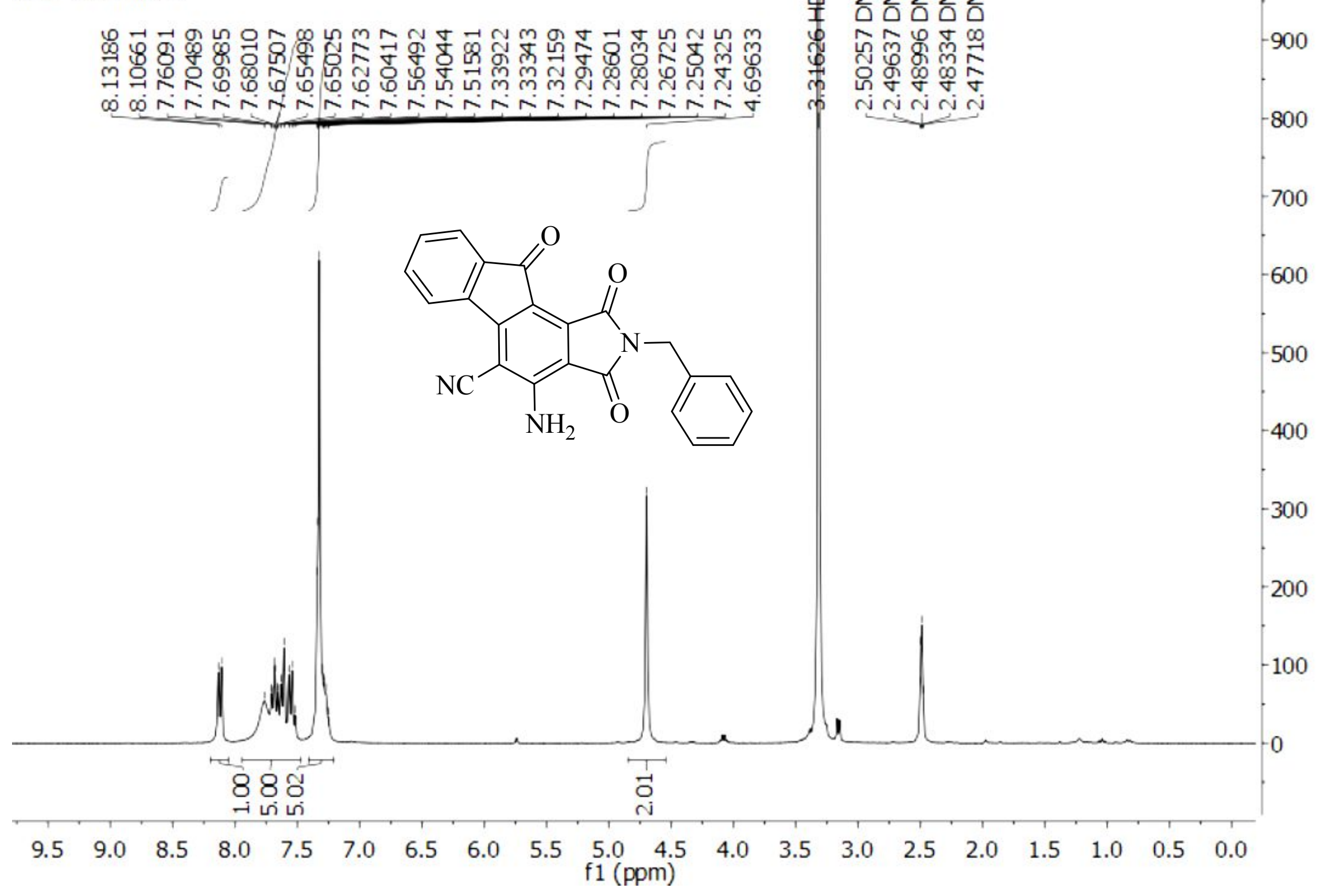

${ }^{1} \mathrm{H}$ NMR (DMSO- $d_{6}, 300 \mathrm{MHz}$ ) spectrum of $\mathbf{6}^{\prime} \mathbf{a}$ 


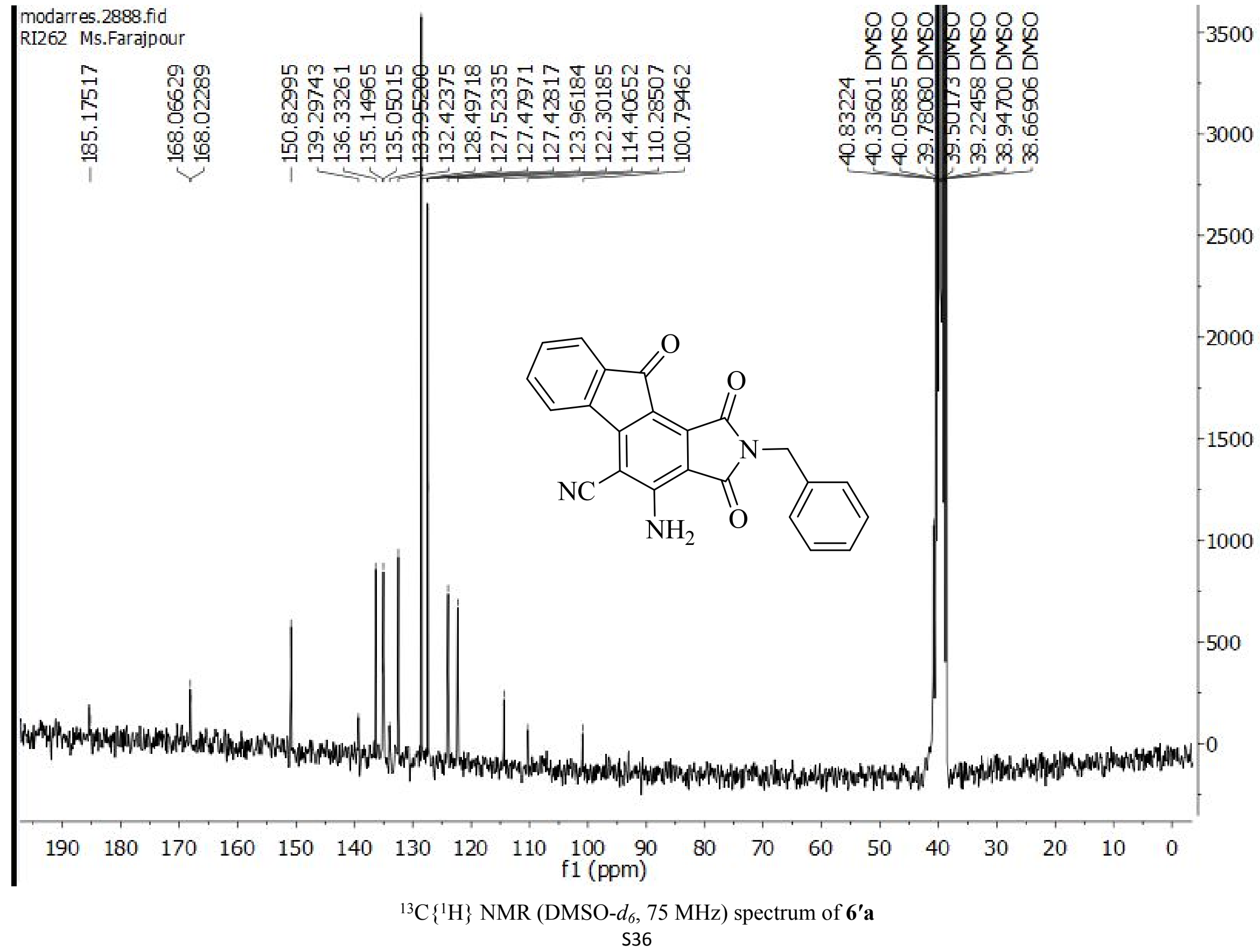




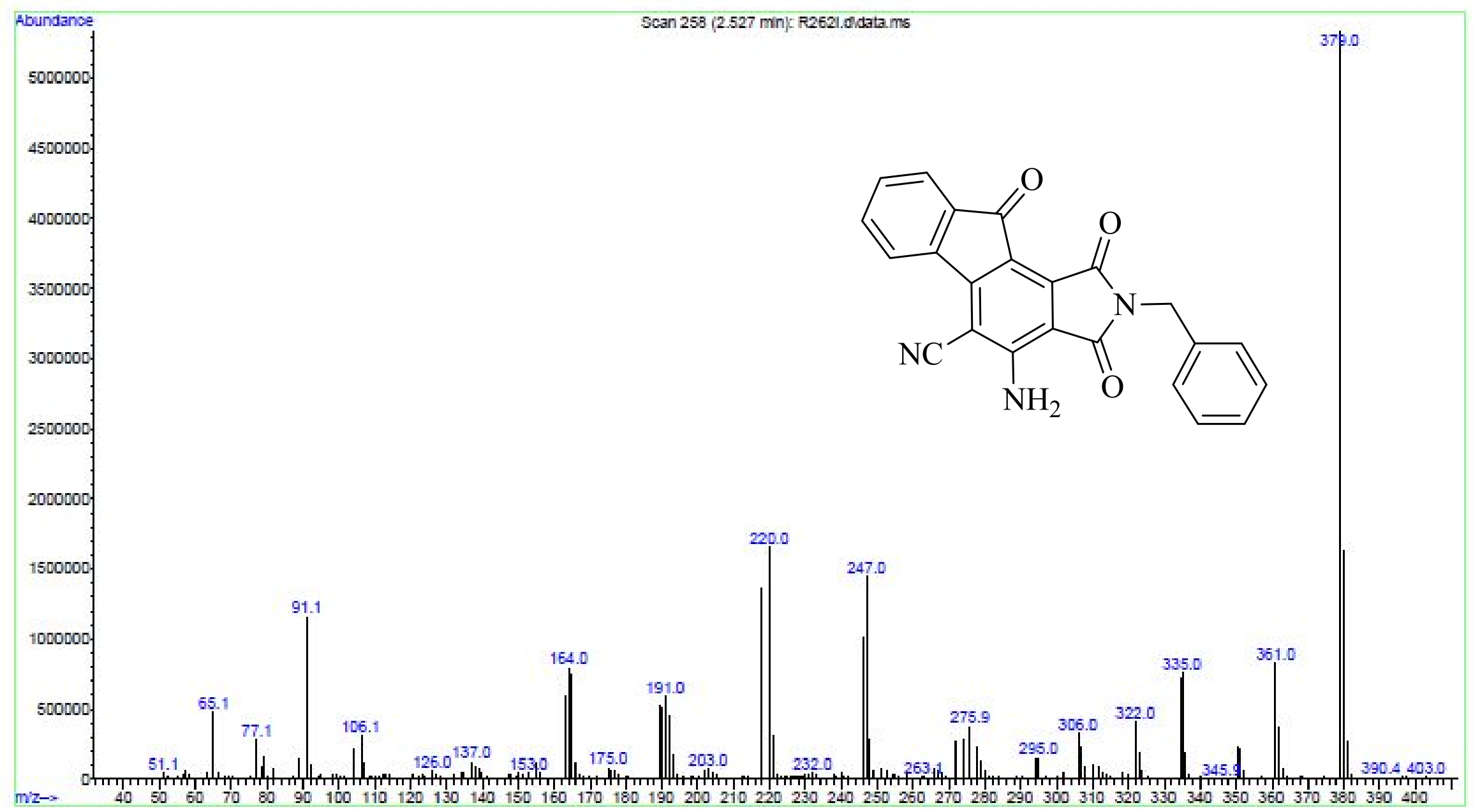

Mass Spectrum of $\mathbf{6}^{\prime} \mathbf{a}$ 


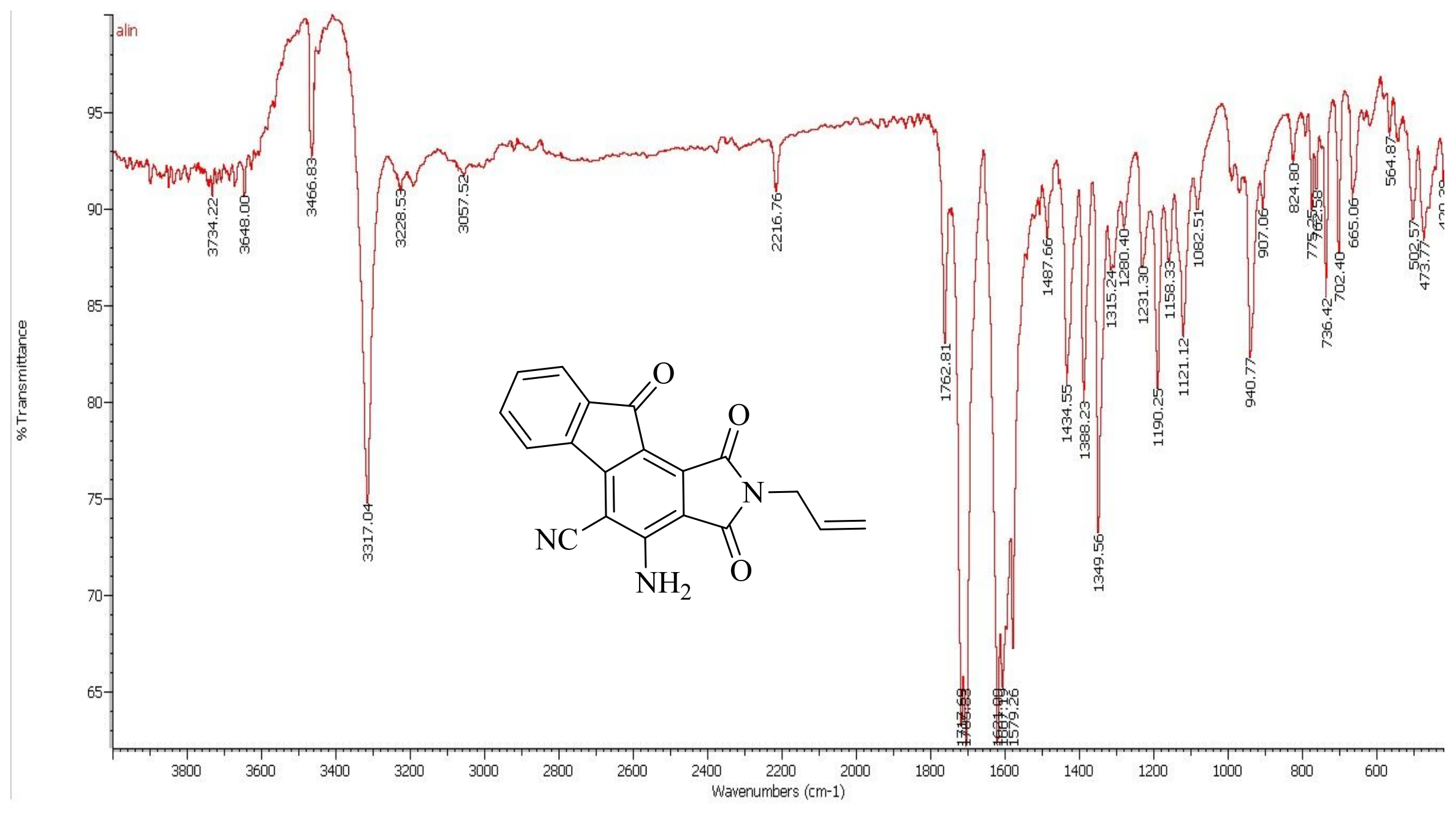

IR Spectrum of $\mathbf{6}^{\prime} \mathbf{b}$ 
สํํํำ

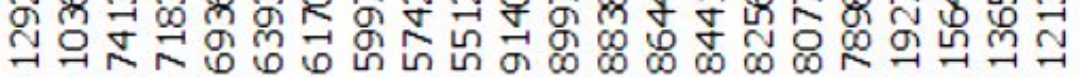
m

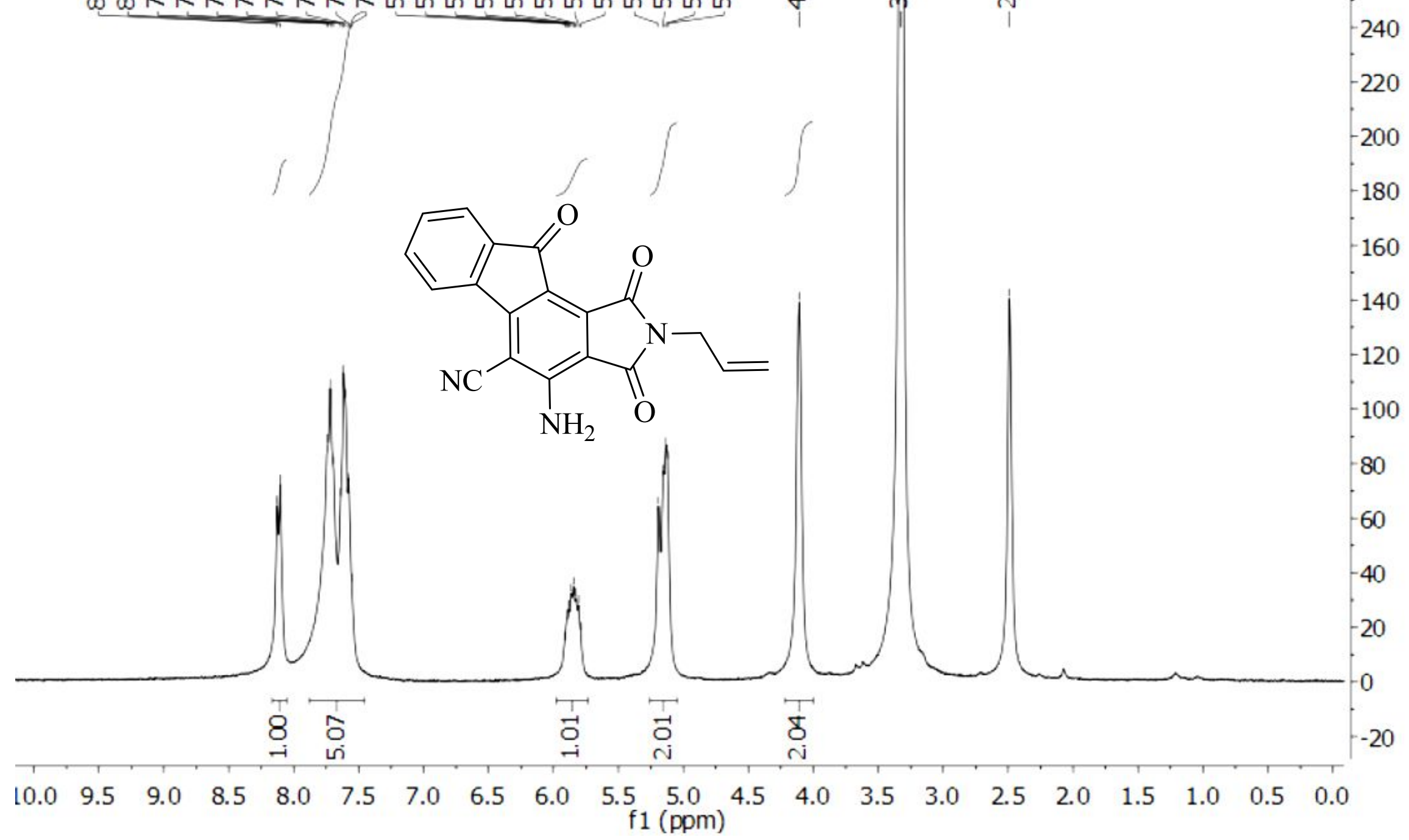

${ }^{1} \mathrm{H}$ NMR (DMSO- $\left.d_{6}, 300 \mathrm{MHz}\right)$ spectrum of $\mathbf{6}^{\prime} \mathbf{b}$ 


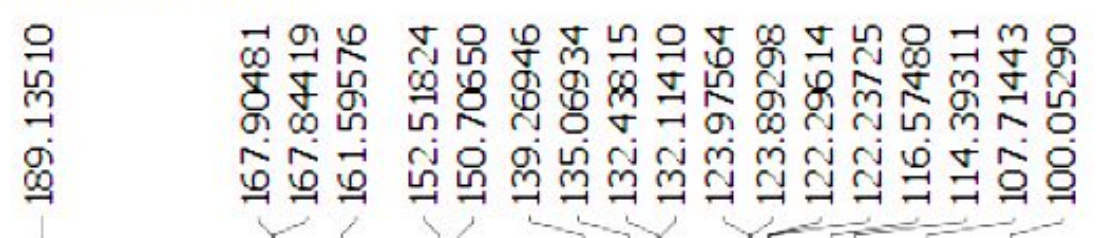




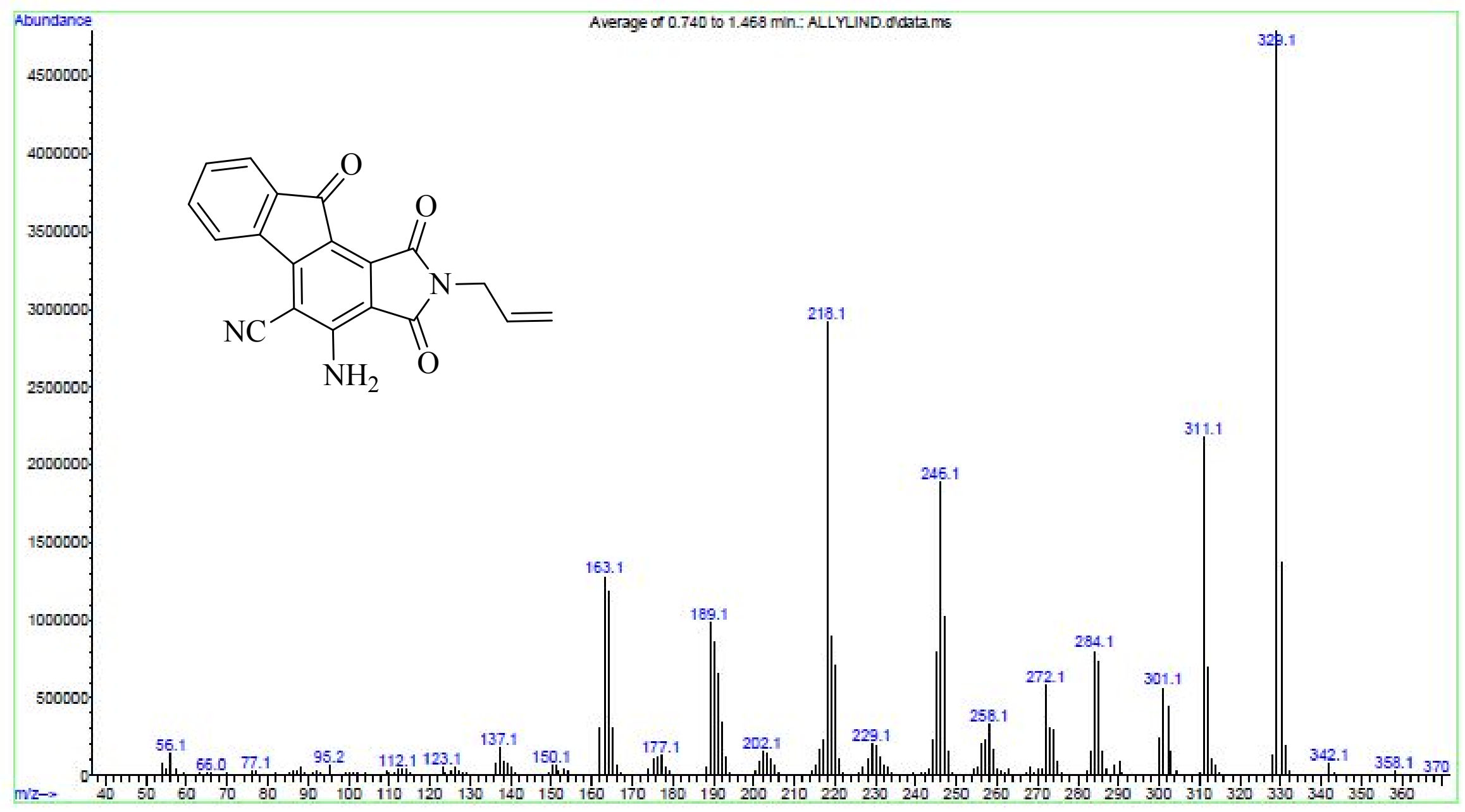

Mass Spectrum of $\mathbf{6}^{\prime} \mathbf{b}$ 


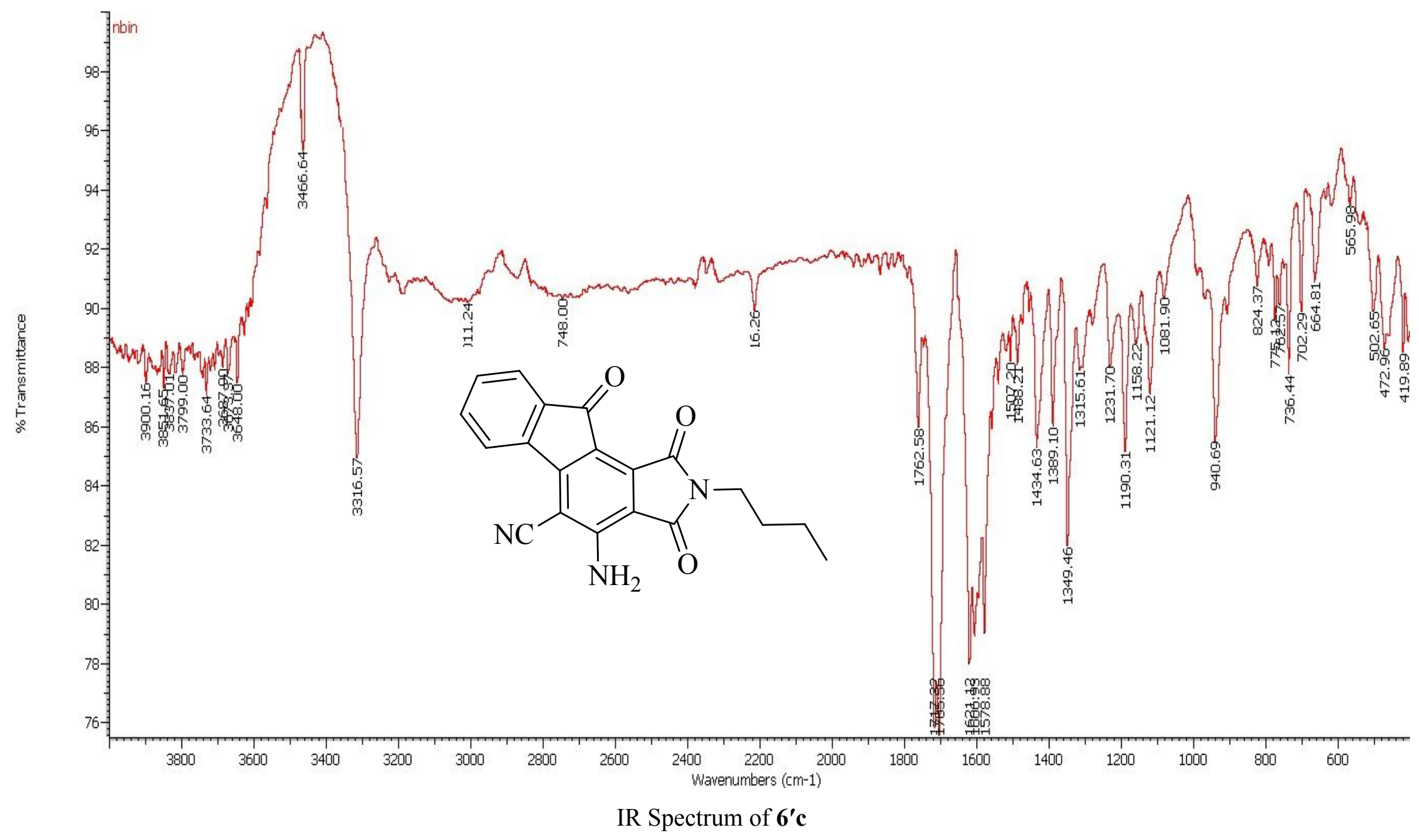



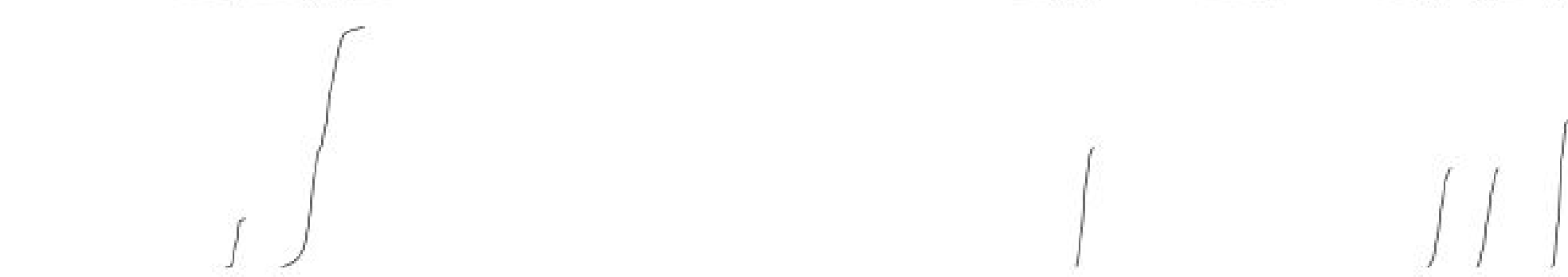<smiles>O=Cc1ccccc1</smiles>

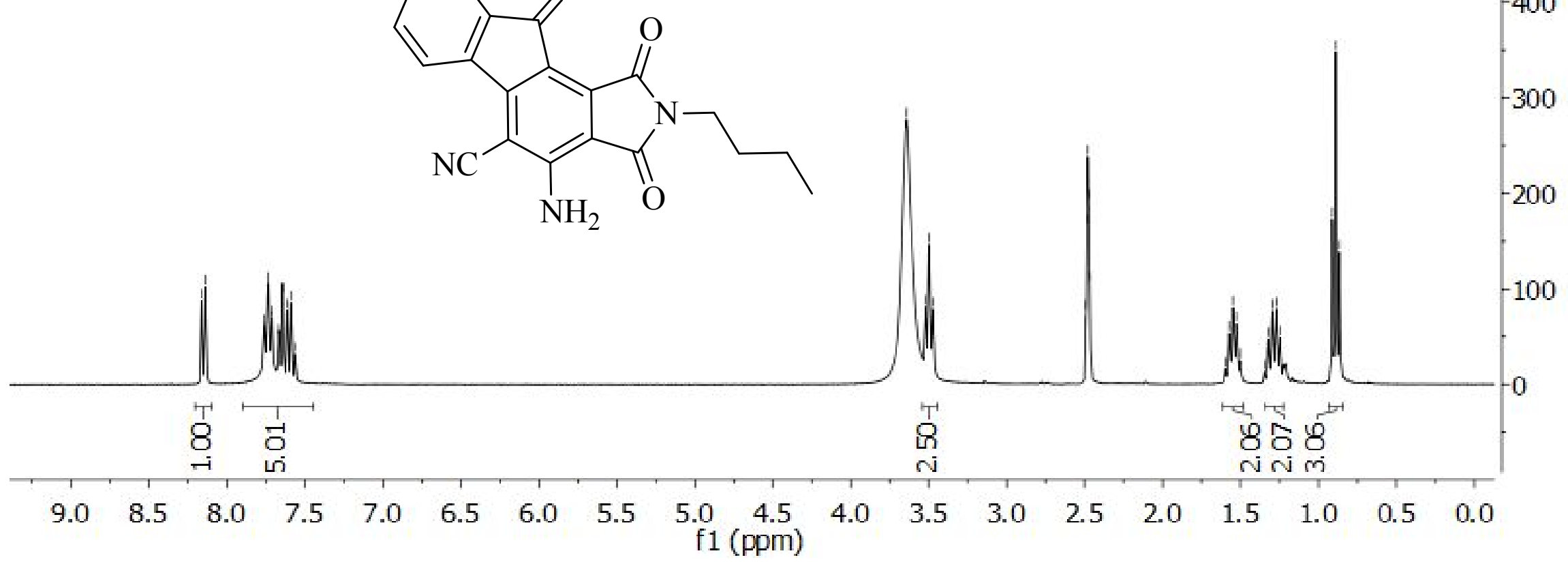

${ }^{1} \mathrm{H}$ NMR (DMSO- $\left.d_{6}, 300 \mathrm{MHz}\right)$ spectrum of $\mathbf{6}^{\prime} \mathbf{c}$ 

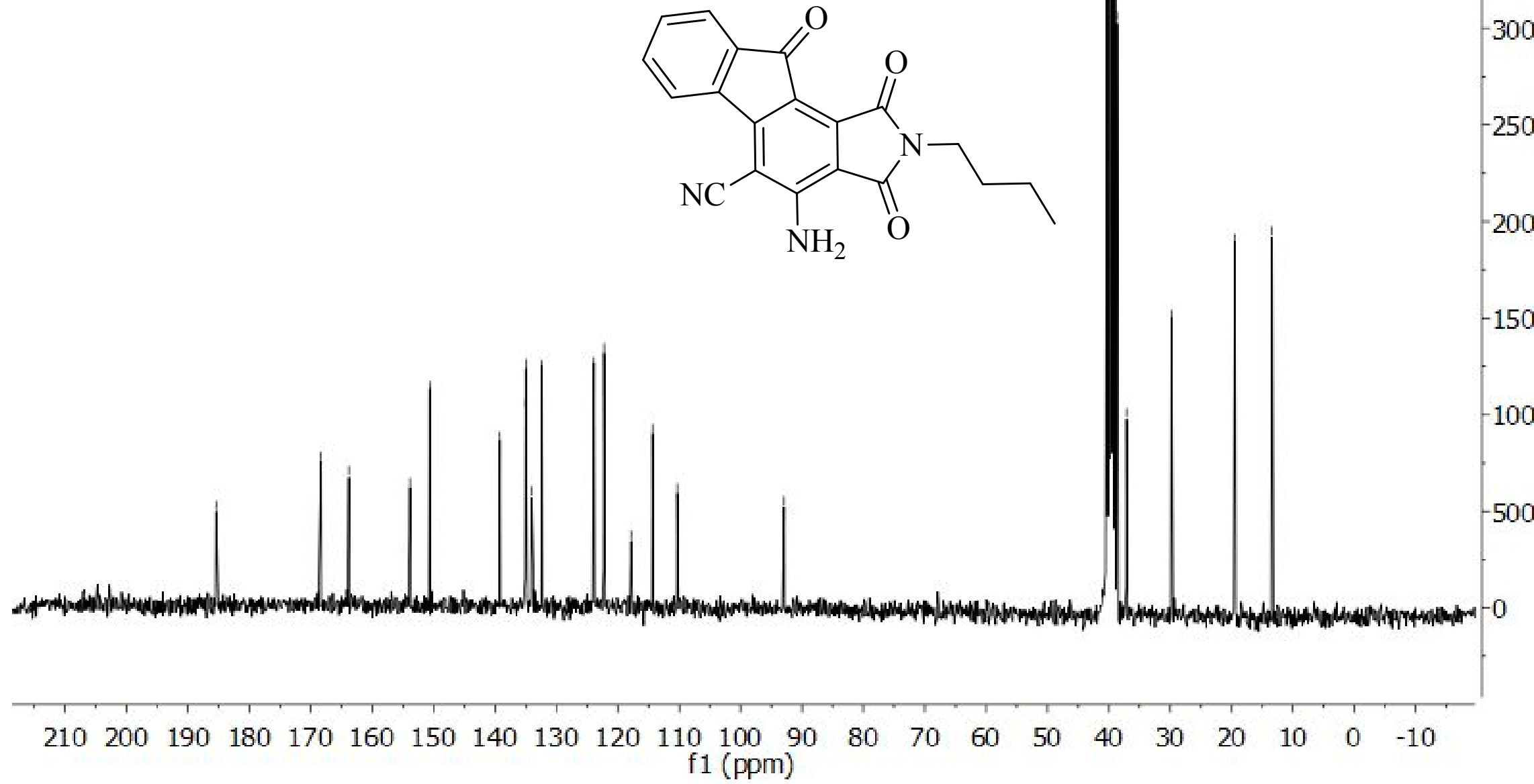

${ }^{13} \mathrm{C}\left\{{ }^{1} \mathrm{H}\right\}$ NMR (DMSO- $d_{6}, 75 \mathrm{MHz}$ ) spectrum of $\mathbf{6}^{\mathbf{6}} \mathbf{c}$ 


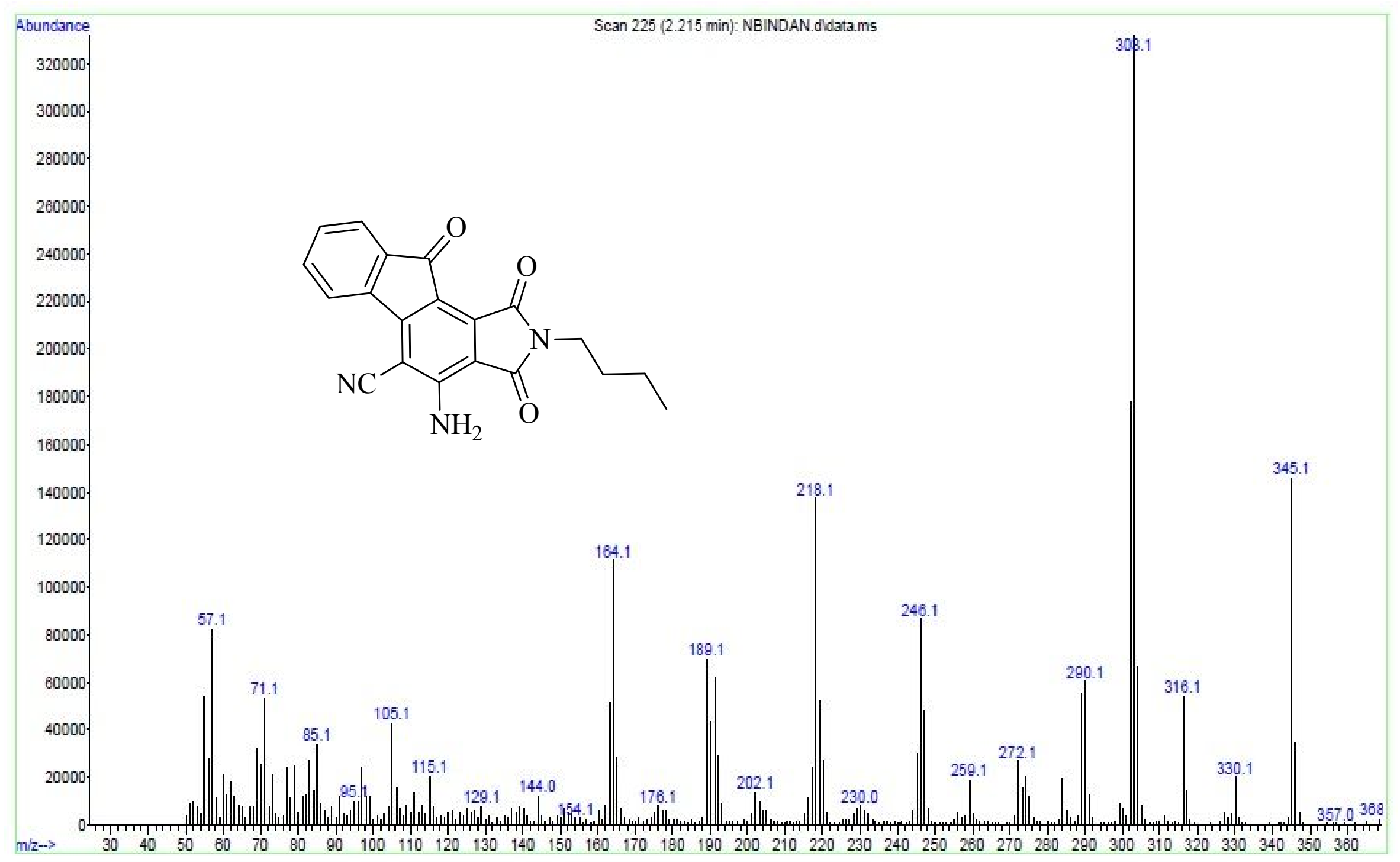

Mass spectrum of $\mathbf{6}^{\prime} \mathbf{c}$ 


\section{Crystallographic Data of 6'a}

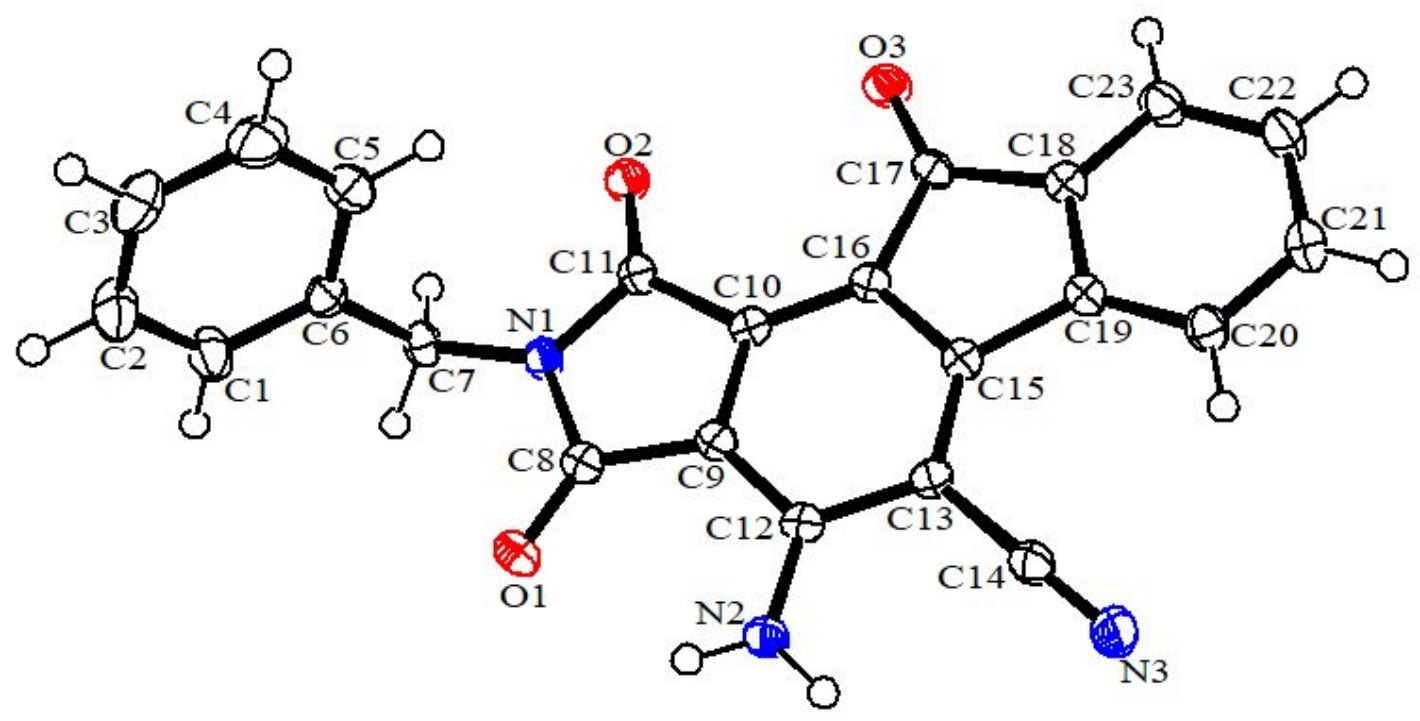

Ortep diagram of compound $\mathbf{6 a}^{\prime}$. The ellipsoid contour of probability level is $50 \%$.

Crystal growth: $5 \mathrm{mg}$ of compound 6'a was dissolved in hot DMSO (2 mL), the solution was cooled slowly and single crystals were formed.

Crystal data for 6'a $\mathrm{C}_{23} \mathrm{H}_{13} \mathbf{N}_{3} \mathrm{O}_{3}\left(\mathbf{C C D C}\right.$ 1955507): $\mathrm{M}_{\mathrm{W}}=379.36$, monoclinic, $\mathrm{P} 21 / \mathrm{c}, \mathrm{a}=$ 12.122(2) $\AA, \mathrm{b}=16.216(3) \AA, \mathrm{c}=8.839(2) \AA, \alpha=90.00(3), \beta=91.52(3), \gamma=90.00(3), \mathrm{V}=$ 1737.0(6) $\AA^{3}, \mathrm{Z}=1, \mathrm{Dc}=1.451 \mathrm{mg} / \mathrm{m}^{3}, \mathrm{~F}(000)=784$, crystal dimension $0.30 \times 0.30 \times 0.30 \mathrm{~mm}$, radiation, $\mathrm{Mo} \mathrm{K} \alpha(\lambda=0.71073 \AA), 1.680 \leq 2 \theta \leq 27.589$, intensity data were collected at $136(2) \mathrm{K}$ with a Bruker APEX area-detector diffractometer, and employing $\omega / 2 \theta$ scanning technique, in the range of $-15 \leq \mathrm{h} \leq 15,-21 \leq \mathrm{k} \leq 21,-11 \leq 1 \leq 11$; the structure was solved by a direct method, all non-hydrogen atoms were positioned and anisotropic thermal parameters refined from 4019 observed reflections with $\mathrm{R}$ (into) $=0.0232$ by a full-matrix least-squares technique converged to $\mathrm{R} 1=0.0355$, and $\mathrm{wR} 2=0.0920[\mathrm{I}>2 \operatorname{sigma}(\mathrm{I})]$. 